\title{
Zero Discharge Water Management for Horizontal Shale Gas Well Development
}

Final Report

Start Date:

End Date:

Authors:

Report Date Issued:

DOE Award \#:

Submitting Organization:
October 1, 2009

March 31, 2012

Paul Ziemkiewicz, $\mathrm{PhD}$

Jennifer Hause

Raymond Lovett, $\mathrm{PhD}$

David Locke

Harry Johnson

Doug Patchen, PG

June 2012

DE-FE0001466

West Virginia Water Research Institute

West Virginia University

PO Box 6064

Morgantown, WV 26506-6064

FilterSure, Inc.

PO Box 1277

McLean, VA 22101

ShipShaper, LLP

PO Box 2

Morgantown, WV 26507 


\title{
Acknowledgment
}

"This material is based upon work supported by the Department of Energy under Award Number DE-FE0001466."

\section{Disclaimer}

"This report was prepared as an account of work sponsored by an agency of the United States Government. Neither the United States Government nor any agency thereof, nor any of their employees, makes any warranty, express or implied, or assumes any legal liability or responsibility for the accuracy, completeness, or usefulness of any information, apparatus, product, or process disclosed, or represents that its use would not infringe privately owned rights. Reference herein to any specific commercial product, process, or service by trade name, trademark, manufacturer, or otherwise does not necessarily constitute or imply its endorsement, recommendation, or favoring by the United States Government or any agency thereof. The views and opinions of authors expressed herein do not necessarily state or reflect those of the United States Government or any agency thereof."

\begin{abstract}
Hydraulic fracturing technology (fracking), coupled with horizontal drilling, has facilitated exploitation of huge natural gas (gas) reserves in the Devonian-age Marcellus Shale Formation (Marcellus) of the Appalachian Basin. The most-efficient technique for stimulating Marcellus gas production involves hydraulic fracturing (injection of a water-based fluid and sand mixture) along a horizontal well bore to create a series of hydraulic fractures in the Marcellus. The hydraulic fractures free the shale-trapped gas, allowing it to flow to the well bore where it is conveyed to pipelines for transport and distribution.
\end{abstract}

The hydraulic fracturing process has two significant effects on the local environment. First, water withdrawals from local sources compete with the water requirements of ecosystems, domestic and recreational users, and/or agricultural and industrial uses. Second, when the injection phase is over, 10 to $30 \%$ of the injected water returns to the surface. This water consists of flowback, which occurs between the completion of fracturing and gas production, and produced water, which occurs during gas production. Collectively referred to as returned frac water (RFW), it is highly saline with varying amounts of organic contamination. It can be disposed of, either by injection into an approved underground injection well, or treated to remove contaminants so that the water meets the requirements of either surface release or recycle use. Depending on the characteristics of the RFW and the availability of satisfactory disposal alternatives, disposal can impose serious costs to the operator. In any case, large quantities of water must be transported to and from well locations, contributing to wear and tear on local roadways that were not designed to handle the heavy loads and increased traffic. The search for a way to mitigate the situation and improve the overall efficiency of shale gas production suggested a treatment method that would allow RFW to be used as make-up water for successive 
fracs. RFW, however, contains dissolved salts, suspended sediment and oils that may interfere with fracking fluids and/or clog fractures. This would lead to impaired well productivity. The major technical constraints to recycling RFW involves: identification of its composition, determination of industry standards for make-up water, and development of techniques to treat RFW to acceptable levels. If large scale RFW recycling becomes feasible, the industry will realize lower transportation and disposal costs, environmental conflicts, and risks of interruption in well development schedules. 


\section{Table of Contents}

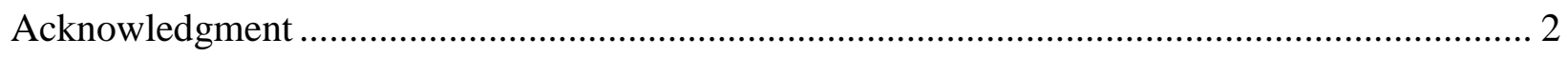

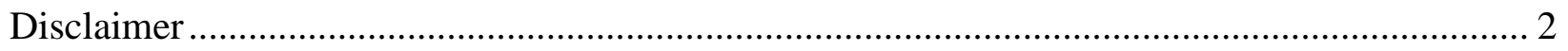

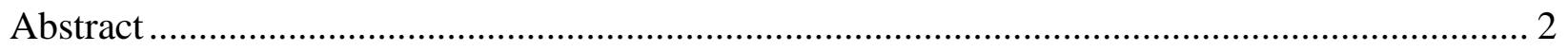

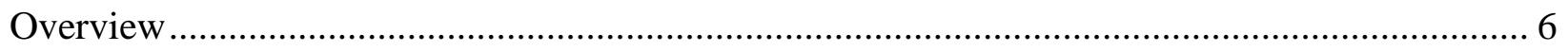

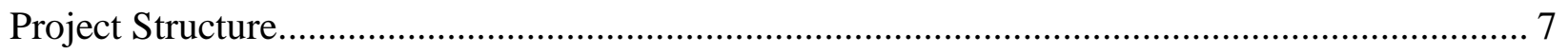

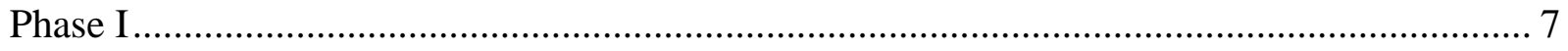

Recommendations of the Industry Contact Group........................................................... 7

Table 1: Industry Contact Group Chemical Criteria for Frac Water Make-up ................ 8

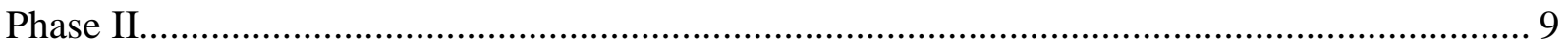

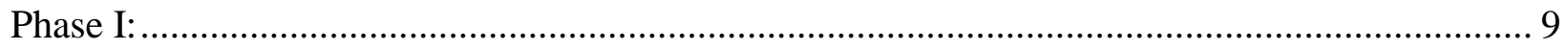

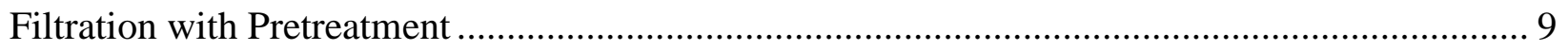

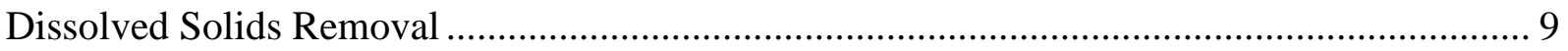

Table 2: $\quad$ Costs of Various Treatment Methods........................................................... 10

Figure 1: Comparison of Cost and Efficiency for Nanofiltration and RO....................... 11

Figure 2: Comparison of Cost and Flow of Nanofiltration and RO................................ 11

Figure 3: Comparison of Cost and Electricity Cost of Nanofiltration and RO............... 12

Table 3: $\quad$ Chemical Results of Raw Samples of RFW .................................................... 13

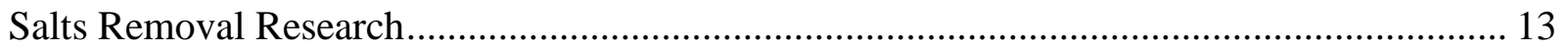

Table 4: $\quad$ Frac Water Treatment Using 44\% 2-propanol ................................................... 14

Table 5: $\quad$ Frac Water Evaluated w/ Ammonia (Bottle Method, mean of 3 trials) .......... 15

Table 6: $\quad$ Frac Water Evaluated w/ 2-propanol (Bottle Method, mean of 3 trials)......... 16

Table 7: $\quad$ Frac Water Evaluated w/ 2-propanol (Beaker Method, mean of 3 trials) ....... 17

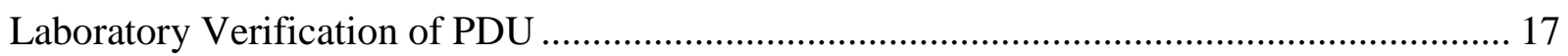

Figure 4: Media Testing of PDU for Treating Marcellus RFW ..................................... 18

Table 8: $\quad$ Summary of PDU and Laboratory Test Data ................................................ 19

Figure 5: $\quad$ PSD Before and After FilterSure Filtration of a RFW Sample ........................ 20

Figure 6: Particle Size in Raw and EC-Treated Marcellus RFW .................................... 21

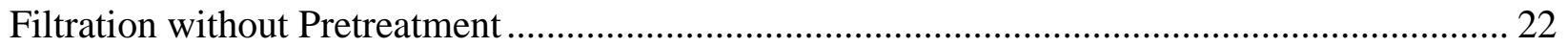

Figure 7: $\quad$ Predicting Stabilized Frac Water TDS when Recycling RFW .............. 24

Table 9: $\quad$ RFW Dilution Model ........................................................................... 25

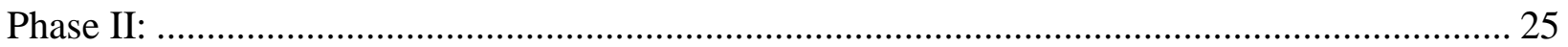

Mobile Treatment Unit Design, Construction and Operations ……………………………....... 25

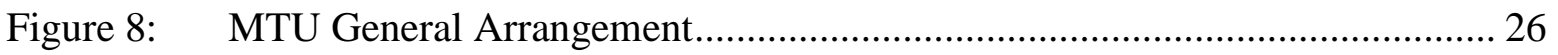


Figure 9: Mobile Treatment Unit Piping Schematic Diagram ................................... 27

Figure 10: Finished Exterior View of MTU ........................................................... 27

Figure 11: Completed Interior View of MTU ............................................................. 28

Figure 12: $\quad$ Particle Size Distribution Results ......................................................... 29

Table 10: Filtration Results of Filtered RFW Samples............................................ 30

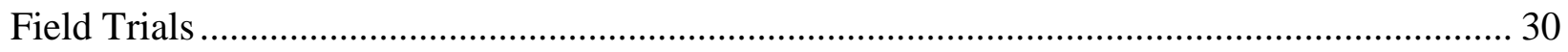

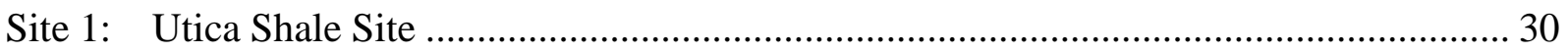

Figure 13: On Location at Utica Shale Site in Ohio ............................................... 31

Figure 14: Oil/Polymer Mixture Treated by MTU …................................................ 32

Figure 15: MTU Control Panel ............................................................................. 33

Figure 16: Control Panel Close-Up View .................................................................. 33

Figure 17: Pressure Drop Measurements of MTU in Operation .................................... 34

Figure 18: Day 1 through Day 6 Filtration Rates and Pressures ................................... 35

Figure 19: Filtration Rate and Pressure, Days 1 through 9 ......................................... 36

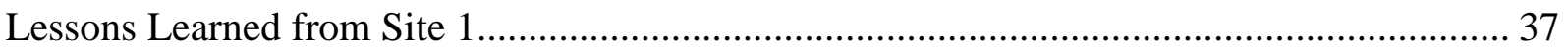

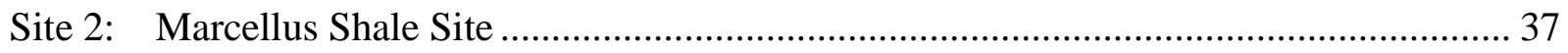

Figure 20: Marcellus Shale Site, West Virginia........................................................ 38

Figure 21: Water Treated for Fracturing Stages .................................................... 39

Figure 22: $\quad$ Rate and Pressure Data during Water Treatment ...................................... 40

Figure 23: Influent and Effluent PSD from West Virginia RFW ................................. 41

Table 11: Marcellus Shale Site Water Chemistry ..................................................... 42

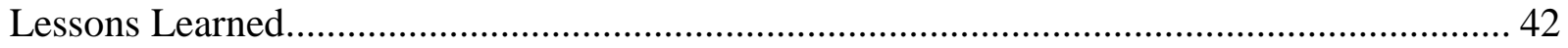

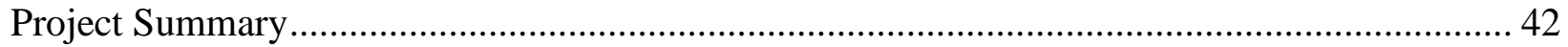

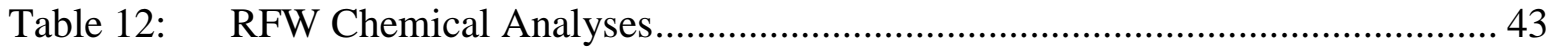

Acronyms, Abbreviations and Units of Measurement...................................................... 45 


\section{Overview}

Shale gas production depends on the creation of permeability within an otherwise nearly impermeable rock formation. Two technologies have been applied to produce natural gas from tight shale formations: directional/horizontal drilling and hydraulic fracturing. Hydraulic fracturing (fracking) uses large volumes of water to create numerous channels within the shale formation. Sand, pumped with the water, props open the hydraulic fractures, thus providing multiple, permeable flow paths for the natural gas.

Terminology used throughout this report to describe various types of water used in the fracking process includes:

1. Frac water - fluid prepared to carry sand (proppant) down-hole under high pressure to create fracs (fissures) in the shale formation;

2. Flowback water - water that returns to the well head in advance of gas production;

3. Produced water - water that returns to the well head with gas during production; and

4. Return frac water (RFW) - flowback and produced water.

RFW is highly variable, changing from well to well and also as a function of time. Besides water and sand, frac water contains a number of chemical additives with the end purpose to enhanced gas production. Unless saline RFW is used to make up the frac water, the frac water will have a low salinity. Flowback water contains a high proportion of the frac water. The salinity of produced water is substantially higher than flowback water, probably due to the longer formation residence time in which the water comes into contact with the formation salts. The Marcellus is known to be desiccated. Otherwise, it would undergo plastic deformation rather than fracture under pressure. Exceptions might occur where the well bore encounters a nontarget formation; but, most of the water that returns from the well is the original injected water, or frac water. Our use of the term RFW recognizes in actual operations, flowback and produced waters are often mixed or otherwise managed as a single commodity.

The hydraulic fracturing process has two significant effects on the local environment. First, water withdrawals from local sources compete with the water requirements of ecosystems, domestic and recreational users, and/or agricultural and industrial uses. Second, when the injection phase is over, 10 to $30 \%$ of the injected water returns to the surface. This water consists of flowback, which occurs between the completion of fracturing and gas production, and produced water, which occurs during gas production. Collectively referred to as returned frac water (RFW), it is highly saline with varying amounts of organic contamination. It can be disposed of, either by injection into an approved underground injection well, or treated to remove contaminants so that the water meets the requirements of either surface release or recycle use. Depending on the characteristics of the RFW and the availability of satisfactory disposal alternatives, disposal can impose serious costs to the operator. In any case, large quantities of water must be transported to and from well locations, contributing to wear and tear on local 
roadways that were not designed to handle the heavy loads and increased traffic. The search for a way to mitigate the situation and improve the overall efficiency of shale gas production suggested a treatment method that would allow RFW to be used as make-up water for successive fracs. RFW, however, contains dissolved salts, suspended sediment and oils that may interfere with fracking fluids and/or clog fractures. This would lead to impaired well productivity. The major technical constraints to recycling RFW involves: identification of its composition, determination of industry standards for make-up water, and development of techniques to treat RFW to acceptable levels. If large scale RFW recycling becomes feasible, the industry will realize lower transportation and disposal costs, environmental conflicts, and risks of interruption in well development schedules.

On October 1, 2009, the United States Department of Energy's (DOE) National Energy Technology Laboratory (NETL) awarded West Virginia University (WVU) a cost-sharing contract to evaluate techniques to be used or adapted to treat RFW. The project resulted from a DOE Funding Opportunity Announcement (FOA) to encourage research of methods to managing hydraulic fracturing water withdrawals and RFW from gas development in the Marcellus. Filtration was considered a critical step in treating RFW for recycle. In developing the project for DOE, WVU partnered with FilterSure, Inc. a developer of a multi-media filter. The project was designed to characterize RFW, identify industry standards for make-up water, evaluate treatment methods, and determine if pairing a technology with filtration was necessary and economically feasible to treat RFW prior to recycling for subsequent fracking operations.

\section{Project Structure}

\section{Phase I}

Phase I objectives included the determination of water quality requirements for frac water makeup by compiling information on hydraulic fracturing practices, shale gas production practices,

and associated problems in the Appalachian shale formations. This led to the development and adaptation of advanced water treatment and filtration technologies that would convert the RFW into a usable substitute of fresh water for hydraulic fracturing. A Technology Status Report was compiled and provided an overview of current industry practices and associated costs to treat and/or dispose of RFW. The analysis indicated treatment and reuse of RFW for another drilling operation was a promising water management option and focused the project on treatment toward that goal.

\section{Recommendations of the Industry Contact Group}

An Industry Contact Group was identified and a detailed questionnaire was sent to the members. Responses yielded valuable information regarding RFW volumes and criteria necessary for recycling. The Industry Contact Group provided access to well development sites, water samples for testing by the FilterSure process demonstration unit (PDU) and invaluable advice 
regarding configuration of our field-deployable technology to match the contingencies of field operations. Some key results from discussions with the Industry Contact Group included:

- slickwater hydraulic fracturing was confirmed as the dominant type of stimulation treatment;

- water demand for most horizontal wells range from about 4 to 6 million gallons, with up to 10 stages, and as much as 250 tons of sand per stage;

- vertical well hydraulic fracturings are similar in size to a single horizontal well stage, $500,000+$ gallons, usually in a single stage, with a total of 250 to 500 tons of sand;

- RFW is approximately $10-30 \%$ of the amount injected. Flow is greatest during the first few days of water flow back and greatly reduced after the first week to 10 days, with initial flow back rates averaging 3,000 to 5,000 barrels per day (90 to 150 gallons per minute (gpm)) and declining to less than a barrel per day after 60 days; and

- horizontal and vertical fracs are both successful but horizontal wells appear to provide better economics.

Industry standards for acceptable recycle water quality standards continued to evolve. The consensus from the Industry Contact Group concerning acceptable water quality for recycled RFW indicated total suspended solids (TSS) below 20 microns along with a range of other parameters presented in Table 1. The TSS criteria reflects concerns with sediment accumulating in pores and the well bore while the chemical water quality parameters are thought to play a role in interfering with the performance of the frac water or with scale formation.

Table 1: Industry Contact Group Chemical Criteria for Frac Water Make-up

\begin{tabular}{|cr|}
\hline Chemical Parameter & Maximum Value (mg/L)* \\
\hline TDS & 50,000 \\
\hline Hardness $^{*}$ & 26,000 \\
\hline $\mathrm{HCO}_{3}$ & 300 \\
\hline $\mathrm{SO}_{4}$ & 50 \\
\hline $\mathbf{C l}$ & 45,000 \\
\hline $\mathbf{N a}$ & 36,000 \\
\hline $\mathbf{C a}$ & 8,000 \\
\hline $\mathbf{M g}$ & 1,200 \\
\hline $\mathbf{K}$ & 1,000 \\
\hline $\mathbf{F e}$ & 10 \\
\hline $\mathbf{B a}$ & 10 \\
\hline $\mathbf{S r}$ & 10 \\
\hline $\mathbf{M n}$ & 10 \\
\hline Requirements of Industry Contact Group Members & \\
\hline &
\end{tabular}


Industry also required a treatment system with minimal operational and maintenance needs and a small footprint with minimal mobilization and de-mobilization requirements. Upon review of the laboratory tests results and multiple discussion sessions with Industry representatives, the project team determined that the multi-media filtration system was a necessary step in any treatment scheme. Removal of dissolved solids was considered important but not critical since most of the criteria in Table 1 could be achieved through dilution with fresh water make-up. Nonetheless, the project proceeded with two salt removal approaches: electro-coagulation and a novel process in the conceptual stage of development.

Industry Contact Group recommendations were critical in refining project objectives. The testing and review of various water treatment technologies during Phase I of the project allowed the WVU project team to identify two options with potential for on-site treatment and recycling of RFW:

1. Filtration to reduce suspended solids, and

2. Electro-coagulation (EC) to determine whether or not it could significantly reduce dissolved salts.

\section{Phase II}

Phase II of this project consisted of the design, fabrication and field deployment of a mobile treatment unit (MTU). The objective was to demonstrate a practical technology for TSS removal under actual field operating conditions. A project goal was for the treatment system design to meet the needs of industry while providing a level of environmental protection and adaptability for future water quality and quantity criteria. The successful development of a technology to treat and recycle RFW will advance shale gas development through improved economics and environmental impacts. Improved economics will be achieved by reducing the amount of trucking and disposal of RFW and costs associated with these activities. By reusing the RFW for subsequent hydraulic fractures, the need for fresh water will be reduced. The better you treat the RFW, the higher the blend ratio with fresh water, the less dependence and strain on local water resources, and the less impact on local infrastructure and the surrounding environment.

\section{Phase I:}

\section{Filtration with Pretreatment}

Early in the project, it was decided to test if filtration, which removes suspended solids but few dissolved solids, would benefit by coupling with a process for removing salts. Various processes were examined that included reverse osmosis (RO), nanofiltration, and electro-coagulation (EC).

\section{Dissolved Solids Removal}

A WVU-developed computer program that calculates the unit costs of various treatment methods was revised with the addition of new treatment methods (such as nanofiltration and EC) and 
updated costs. Table 2 shows costs per 1000 gallons for a number of treatment options utilized to manage RFW, including EC. The EC method appeared to be competitively priced among the various options.

Table 2: $\quad$ Costs of Various Treatment Methods

\begin{tabular}{|ll|}
\hline \multicolumn{1}{|c|}{ Treatment Method } & \$ per1000 gallons \\
\hline Surface disposal & $\$ 0.07$ \\
\hline Deep injection well - existing & $\$ 0.66$ \\
\hline Evaporation/infiltration pond w/ spray & $\$ 0.99$ \\
\hline Spray Irrigation & $\$ 1.08$ \\
\hline Microfiltration & $\$ 1.36$ \\
\hline Evaporative pond - Lined-Spray & $\$ 1.97$ \\
\hline Electro-coagulation & $\$ 2.00$ \\
\hline Shallow injection/aquifer renewal & $\$ 2.85$ \\
\hline Evaporative pond/infiltration & $\$ 2.98$ \\
\hline Water hauling & $\$ 4.82$ \\
\hline Deep injection well - new & $\$ 5.64$ \\
\hline Nanofiltration & $\$ 6.15$ \\
\hline Reverse Osmosis & $\$ 6.94$ \\
\hline Evaporative pond - Lined & $\$ 27.56$ \\
\hline
\end{tabular}

Figures 1 through 3 detail some of the initial investigations comparing reverse osmosis and nanofiltration, the former removing all ions while the latter only removed multi-valent ions. These are two proposed technologies for total dissolved solids (TDS) reduction or removal. The graphs compare cost versus process efficiency, cost versus flow, and cost versus electricity cost. In all instances, nanofiltration was cheaper because of its lower pressure requirements. The rise in cost at low efficiency for the first plot is due to increasing reject disposal costs. Low flow also increases the cost due to the fixed costs associated with the system. The increase in cost due to electricity rates is almost linear. 
Figure 1: Comparison of Cost and Efficiency for Nanofiltration and R0

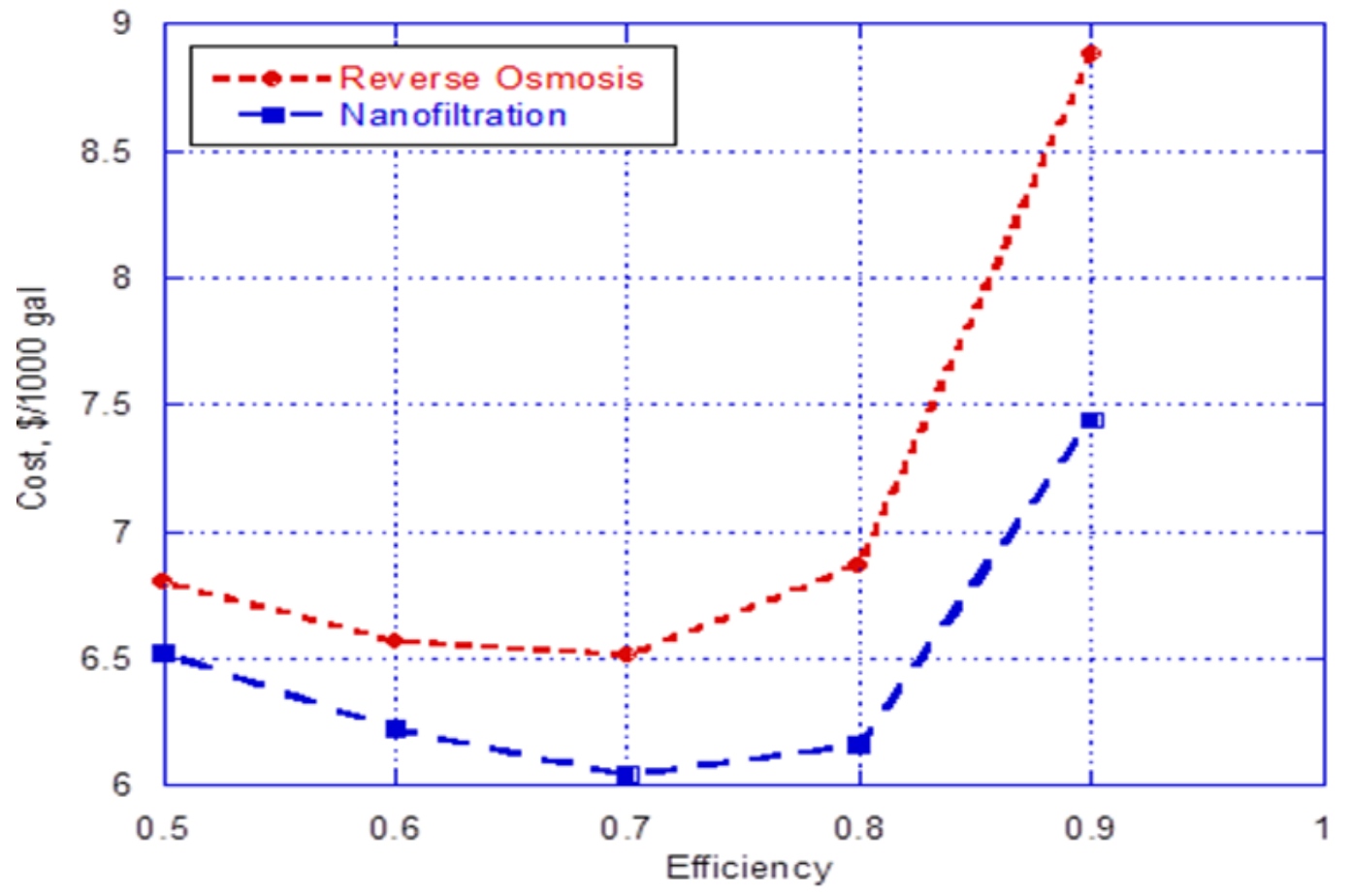

Figure 2: $\quad$ Comparison of Cost and Flow of Nanofiltration and RO

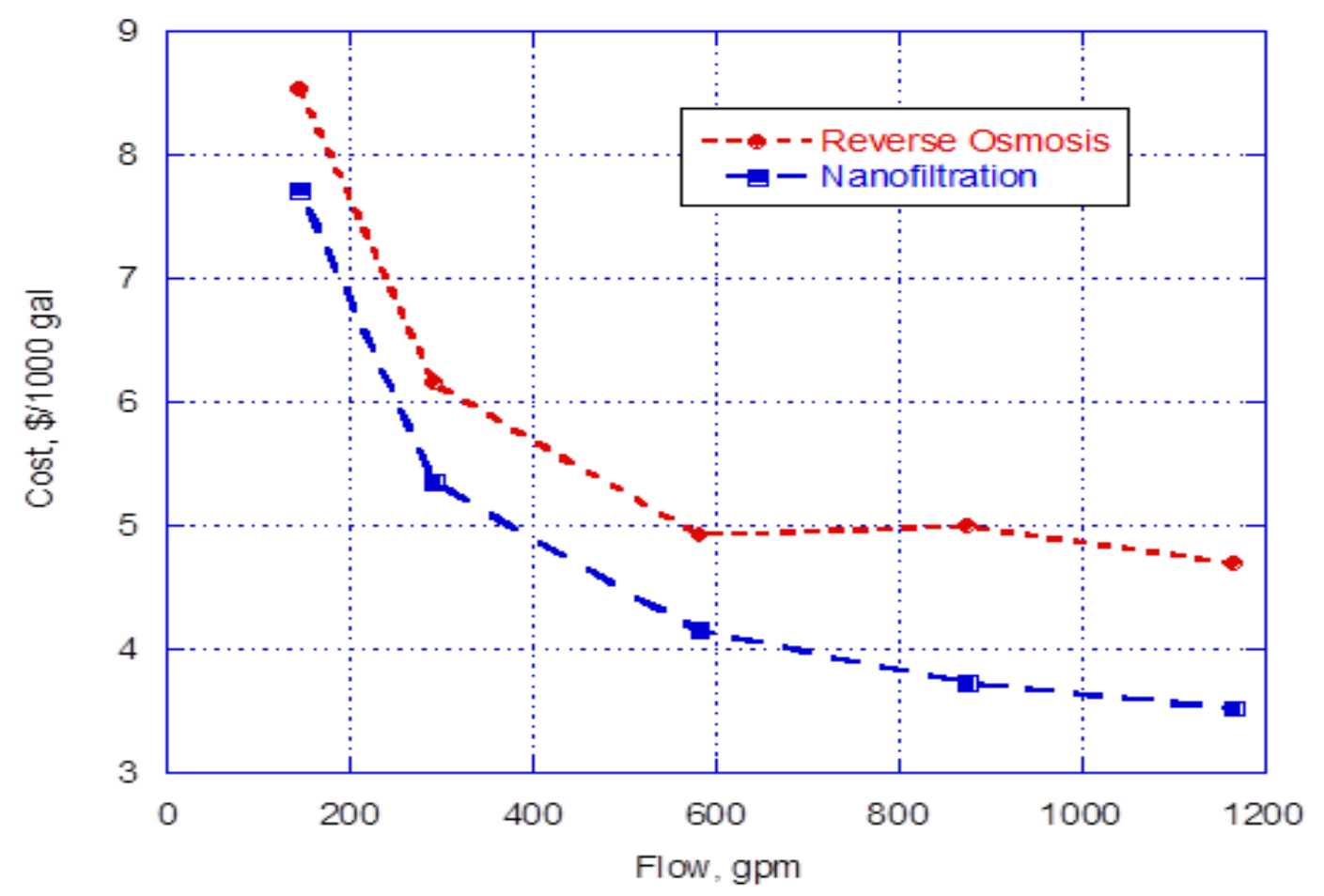


Figure 3: Comparison of Cost and Electricity Cost of Nanofiltration and RO

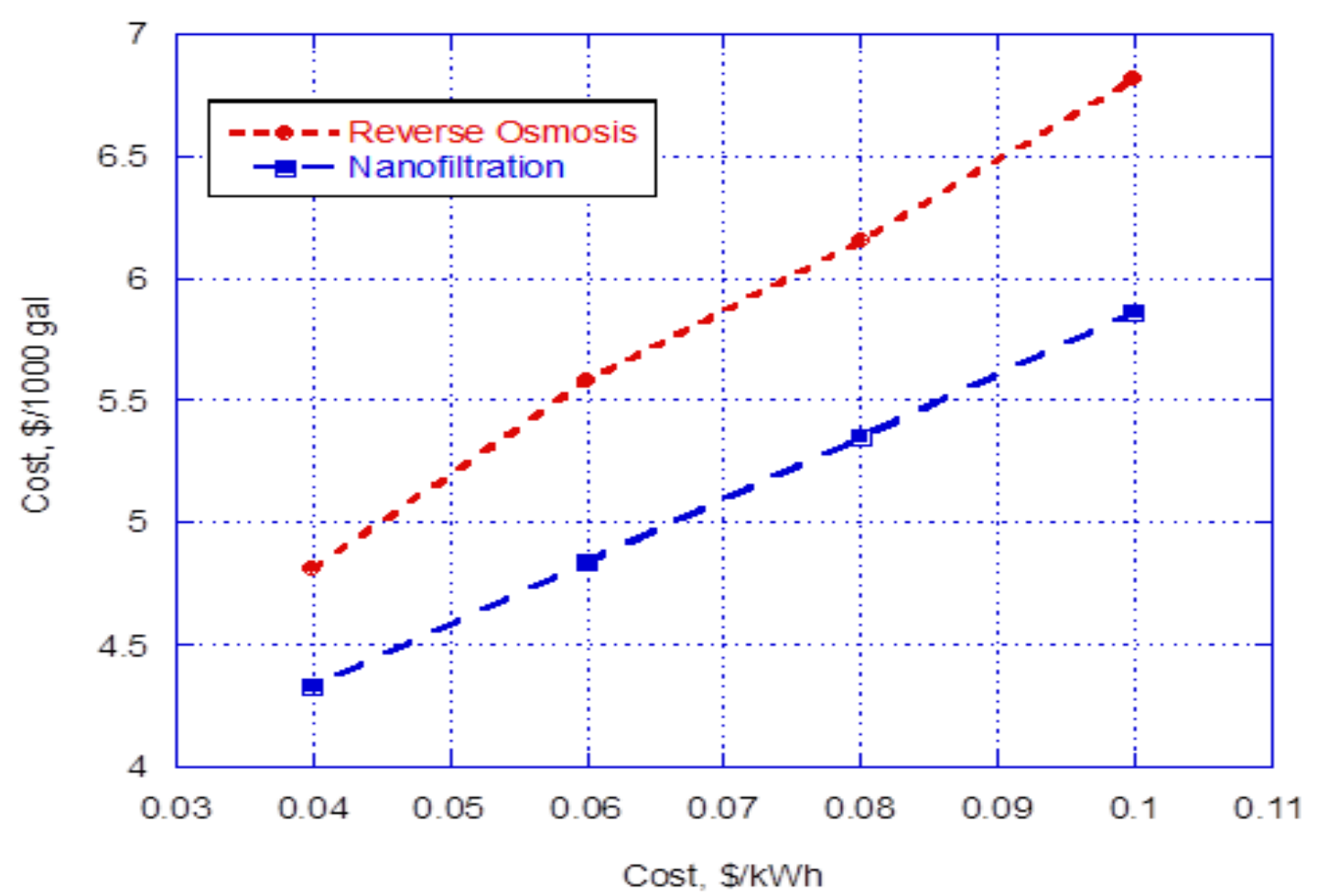

To accurately characterize RFW, the project team analyzed a number of samples provided by the Industry Contact Group. The samples represented RFW from operating sites in New York, Pennsylvania and West Virginia. The samples were drawn from storage tanks or pits and represented a mixture of flowback and produced water. Five samples from the Marcellus and one sample from the Utica shale were tested. Table 3 provides a summary of the chemistry of six raw RFW samples used in this study. 
Table 3: Chemical Results of Raw Samples of RFW

\begin{tabular}{|c|c|c|c|c|c|c|}
\hline & $\begin{array}{c}\text { RFW } \\
\# 1\end{array}$ & $\begin{array}{c}\text { RFW } \\
\# 2\end{array}$ & $\begin{array}{c}\text { RFW } \\
\# 3\end{array}$ & $\begin{array}{c}\text { RFW } \\
\# 4\end{array}$ & $\begin{array}{c}\text { RFW } \\
\# 5\end{array}$ & $\begin{array}{c}\text { RFW } \\
\# 6\end{array}$ \\
\hline pH & 7.46 & 6.1 & 7.4 & 6.3 & 6.3 & 6.7 \\
\hline Conductivity & 23655 & 16807 & 6300 & 190100 & 83000 & 13900 \\
\hline $\mathrm{SO}_{4}$ & 99 & 71 & 28 & nd & 414 & 19 \\
\hline $\mathrm{Fe}$ & 37 & 27 & 37 & 59 & 30 & 27 \\
\hline $\mathrm{Ca}$ & 319 & 1749 & 1640 & 19487 & 12800 & 698 \\
\hline Mg & 31 & 122 & 193 & 1257 & 1470 & 60 \\
\hline $\mathrm{Na}$ & 3550 & 2863 & 8560 & 35500 & 33700 & 2060 \\
\hline $\mathrm{K}$ & nd & 57 & 243 & 479 & 444 & 43 \\
\hline Sr & 0.011 & 0.011 & 301 & 3559 & 1440 & 51 \\
\hline $\mathrm{Ba}$ & 27 & 0 & 175 & 1641 & 176 & 14 \\
\hline Cl & 6575 & 7172 & 17100 & 112457 & 65000 & 4600 \\
\hline TSS & 44 & 220 & 99 & 74 & 570 & 25 \\
\hline TDS & 16559 & 11765 & 46410 & 133070 & 128100 & 9730 \\
\hline Hardn & 923 & 4870 & 4890 & 53836 & 38000 & 1990 \\
\hline Oil \& Grease & 5 & 49 & 5 & 33 & nd & $\mathrm{n}$ \\
\hline
\end{tabular}

nd $=$ not detected

\section{Salts Removal Research}

Removal of highly soluble ions is difficult. As mentioned, reverse osmosis and nano-filtration are able to remove the ions at a high cost. Electro-coagulation was found to be ineffective. Preliminary research to determine the technical feasibility of using methods of dielectric lowering to remove salts was conducted. Ideally, this method would be coupled with the FilterSure filtration system for solids removal.

Preliminary research on methods for removal of salts using dielectric reduction with solvents and mixed solvent systems was conducted. The aqueous solubility for potassium chloride $(\mathrm{KCl})$ was determined to be $34.5 \mathrm{gm} / 100 \mathrm{gm}$ of water. Investigations of mixed solids beginning with the use of 2-propanol followed to evaluate solubility and conductivity. The solubility of $\mathrm{KCl}$ in 2propanol/water mixtures showed that the initial $26 \% \mathrm{KCl}$ by weight dropped to nearly $1 \%$ when the solvent was $80 \%$ 2-propanol by weight. The concentration, referenced to the original water, decreased from $345,000 \mathrm{mg} / \mathrm{L}$ to approximately $40,000 \mathrm{mg} / \mathrm{L}$. Removal of the precipitated salt followed by removal of the 2-propanol resulted in an $88 \%$ reduction of salt.

Experiments with potassium sulfate $\left(\mathrm{K}_{2} \mathrm{SO}_{4}\right)$ showed $90 \%$ less solubility with $20 \%$ (w/w) 2propanol than pure water. Although the analyses were conducted at $22^{\circ} \mathrm{C}$, and not at $50^{\circ} \mathrm{C}$, $\mathrm{K}_{2} \mathrm{SO}_{4}$ would be more soluble at the higher temperature. 
Potassium sulfate was found to have a solubility of $11.17 \mathrm{gm} \mathrm{K}_{2} \mathrm{SO}_{4} / 100 \mathrm{gm}$ of water using the method developed earlier. The literature solubility is $12 \mathrm{gm} / 100 \mathrm{gm}$. The solubility of $\mathrm{K}_{2} \mathrm{SO}_{4}$ in a 20:80 w/w 2-propanol:water mixture was found to be $0.98 \mathrm{gm} / 100 \mathrm{gm}$ solvent.

One hundred milliliters $(\mathrm{mL})$ of hydraulic fracturing water was also treated with 2-propanol, resulting in a lowering of the conductivity by about half. The behavior was tracked using conductivity. Lower conductivity is a complex function of solution dielectric changes and salt loss. The solution was recovered through filtering after addition of $80 \mathrm{gm}$ of 2-propanol. The 2propanol was evaporated, regenerating an aqueous solution that had a conductivity of 97 microsiemens per centimeter $(\mu \mathrm{S} / \mathrm{cm}), 50.5 \%$ of the original value. Comparison of salt content of the original and final solutions showed $24 \%$ of the original sodium $(55,000 \mathrm{mg} / \mathrm{L})$ and $37 \%$ of the original chloride (100,000 mg/L) were removed, yielding 41,800 mg/L sodium and 63,000 mg/L chloride. The final added 2-propanol, $80 \mathrm{gm}$, corresponded to a solution that was $44 \% 2$ propanol. When converted to molar concentration, $0.57 \mathrm{M}$ of sodium is removed and $1 \mathrm{M}$ of chloride. Other ions must be involved in chloride removal, 1:1 molar removal is expected for sodium chloride $(\mathrm{NaCl})$. The resultant solution was analyzed for the major ions, Table 4 , showing significant reductions in the divalent cations calcium, strontium and barium.

Table 4: $\quad$ Frac Water Treatment Using 44\% 2-propanol

\begin{tabular}{cccc}
\hline Ion & Original water, mg/L & Treated water, $\mathbf{m g} / \mathbf{L}$ & Percent reduction \\
\hline Ca & 21200 & 423 & 98 \\
Sr & 2970 & $<0.011$ & $\sim 100$ \\
Ba & 1280 & $<0.012$ & $\sim 100$ \\
\hline
\end{tabular}

Ammonia was chosen to be the eventual agent due to its ease of removal from solution. Initial studies used a $25 \%(\mathrm{w} / \mathrm{w})$ aqueous ammonia solution. A new method was developed to avoid dilution of the ammonia. The solubility was determined by evaporating the water from the sample then reconstituting it in the $25 \%$ ammonia. The method was tested using $\mathrm{K}_{2} \mathrm{SO}_{4}$ and water. The solubility found using the new method was $11.88 \mathrm{gm} \mathrm{K}_{2} \mathrm{SO}_{4} / 100 \mathrm{gm}$ water, which is in better agreement with the literature value than the original method. The solubility of $\mathrm{K}_{2} \mathrm{SO}_{4}$ in the $25 \%$ ammonia solution was determined to be $0.43 \mathrm{gm} / 100 \mathrm{gm}$ solvent. A literature value is $0.22 \mathrm{gm} / 100 \mathrm{gm}$ solvent with $25.2 \%$ ammonia at $20^{\circ} \mathrm{C}$.

The analytical results (measurements of solution concentrations of the recovered water) for $\mathrm{K}_{2} \mathrm{SO}_{4}$ solubility in ammonia showed sulfate concentrations near $1200 \mathrm{mg} / \mathrm{L}$. This value corresponds to about $0.22 \mathrm{gm} / 100 \mathrm{~g} \mathrm{~m}$ solvent (although the volume has changed due to ammonia evaporation). The analytical results are disquieting for potassium. The potassium concentration should be near $1000 \mathrm{mg} / \mathrm{L}$, but are reported to be around $1 \mathrm{mg} / \mathrm{L}$. The lack of accuracy implicates all analyses. The solutions for $\mathrm{K}_{2} \mathrm{SO}_{4}$ solubility, for example, should have sulfate 
concentrations near $65,000 \mathrm{mg} / \mathrm{L}$ and $61,000 \mathrm{mg} / \mathrm{L}$ was found. However, very little potassium was found.

The method was applied to mine water and applied to a second hydraulic fracturing water sample. The mine water had a reduction of calcium from $800 \mathrm{mg} / \mathrm{L}$ to roughly $25 \mathrm{mg} / \mathrm{L}$. Sulfate, however, remained roughly the same as in the original sample. This is inconsistent, since gypsum is the least soluble solid for calcium in the system. An analytical error is suspected, probably for calcium. Mine water has a lower TDS content than hydraulic fracturing water and the method will be less effective.

Using what is called the Bottle Method, where the water of concern is evaporated, reconstituted in the solvent of interest and filtered, hydraulic fracturing water was tested with $25 \%$ ammonia and 2-propanol. In addition, the original method, the Beaker Method, where 2-propanol is added to the solution, then evaporated, was used.

The hydraulic fracturing water had an initial $\mathrm{pH}$ of 6.6. After re-dissolving the salt in ammonia solution, then driving off much of the ammonia, the $\mathrm{pH}$ was 8.2. The solution contained 680 $\mathrm{mg} / \mathrm{L}$ ammonia nitrogen, $826 \mathrm{mg} / \mathrm{L}$ ammonia, which indicates over $96 \%$ removal of ammonia. The conductivity increased from $13.9 \mu \mathrm{S} / \mathrm{cm}^{2}$ to $15 \mu \mathrm{S} / \mathrm{cm}^{2}$, an increase of $7.9 \%$. The increase can be attributed to ammonia.

Ion concentrations shown in Table 5 decreased substantially for the alkaline earth elements magnesium, calcium, strontium and barium $(\mathrm{Mg}, \mathrm{Ca}, \mathrm{Sr}$, and $\mathrm{Ba})$, by one third for sulfate $\left(\mathrm{SO}_{4}\right)$ and marginally for potassium $(\mathrm{K})$ and chloride $(\mathrm{Cl})$. The total dissolved solids for the original hydraulic fracturing water was $9760 \mathrm{mg} / \mathrm{L}$, which is rather low to expect substantial removal by solubility decrease. The solubility of pure $\mathrm{K}_{2} \mathrm{SO}_{4}$ in $25 \%$ ammonia is $0.22 \mathrm{gm} / 100 \mathrm{gm}$ solvent, roughly $2.2 \mathrm{gm} / \mathrm{L}$, far in excess of the $43 \mathrm{mg} / \mathrm{L}$ seen here.

Table 5: $\quad$ Frac Water Evaluated w/ Ammonia (Bottle Method, mean of 3 trials)

\begin{tabular}{cccc}
\hline Ion & riginal water, $\mathbf{~ m g / L}$ & Treated water, $\mathbf{~ m g / L}$ & Percent reduction \\
\hline $\mathbf{C a}$ & 698 & 10.3 & 98.5 \\
$\mathbf{S r}$ & 51 & 7.5 & 86 \\
$\mathbf{B a}$ & 14 & 0.063 & 99.5 \\
$\mathbf{M g}$ & 60 & $<0.5$ & $>99$ \\
$\mathbf{S O}_{4}$ & 19 & 11.9 & 37 \\
$\mathbf{K}$ & 43 & 37.3 & 13 \\
$\mathbf{C l}$ & 4600 & 4160 & 10 \\
\hline
\end{tabular}


The removal of alkaline earth ions is largely through precipitation of their hydroxides at the high $\mathrm{pH}$ of the initial ammonia solution. That solution was filtered, then the ammonia driven off for the final $\mathrm{pH}$ of 8.2. The hydroxide solubilities are $\mathrm{Ba}>\mathrm{Sr}>\mathrm{Ca}>\mathrm{Mg}$. The sulfate solubilities are $\mathrm{Mg}>\mathrm{Ca}>\mathrm{Sr}>\mathrm{Ba}$. The removal order in ammonia is $\mathrm{Ba}>\mathrm{Mg}>\mathrm{Ca}>\mathrm{Sr}$, with barium out of order. The very low barium value is likely due to some barium sulfate precipitation, making it less concentrated than the strontium.

The Bottle Method using 2-propanol, results tabulated in Table 6, is more indicative of dielectric constant lowering. Barium and strontium, the least soluble sulfates, are decreased, while magnesium and calcium are barely removed. The sulfate decrease indicates removal by barium and strontium, although a mass balance does not provide enough sulfates to account for all the strontium. The chloride decrease cannot be balanced by the measured cations. Sodium may be the cation associated with chloride. The hydraulic fracturing water contained $2060 \mathrm{mg} / \mathrm{L}$ sodium, but its removal was not measured in the treated samples. The conductivity decreased to $0.67 \mu \mathrm{S} / \mathrm{cm}^{2}$, a $95 \%$ decrease. Roughly half the salt isolated from the hydraulic fracturing water dissolved in the 2-propanol, whereas $84 \%$ dissolved in the $25 \%$ ammonia solvent.

Table 6: $\quad$ Frac Water Evaluated w/ 2-propanol (Bottle Method, mean of 3 trials)

\begin{tabular}{cccc}
\hline Ion & Original water, $\mathbf{m g} / \mathbf{L}$ & Treated water, $\mathbf{m g} / \mathbf{L}$ & Percent reduction \\
\hline $\mathbf{C a}$ & 698 & 629 & 0.9 \\
$\mathbf{S r}$ & 51 & 14.8 & 71 \\
$\mathbf{B a}$ & 14 & 0.27 & 98 \\
$\mathbf{M g}$ & 60 & 56 & 6.8 \\
$\mathbf{S O}_{\mathbf{4}}$ & 19 & 5.54 & 71 \\
$\mathbf{K}$ & 43 & 4.9 & 89 \\
$\mathbf{C l}$ & 4600 & 1117 & 76 \\
\hline
\end{tabular}

The more practical Beaker Method was conducted using 2-propanol. Two hundred grams of 2propanol were added to 100 grams of the hydraulic fracturing water. The 2-propanol was evaporated and water recovered. Very little solid was generated and with the exception of barium, very little change in concentration for the ions were seen, as presented in Table 7 . The conductivity of the resultant solutions averaged $14 \mu \mathrm{S} / \mathrm{cm}^{2}$. 
Table 7: $\quad$ Frac Water Evaluated w/ 2-propanol (Beaker Method, mean of 3 trials)

\begin{tabular}{cccc}
\hline Ion & Original water, $\mathbf{m g} / \mathbf{L}$ & Treated water, $\mathbf{m g} / \mathbf{L}$ & Percent reduction \\
\hline $\mathbf{C a}$ & 698 & 801 & -15 \\
$\mathbf{S r}$ & 51 & 54.5 & -7 \\
$\mathrm{Ba}$ & 14 & 1.0 & 93 \\
$\mathbf{M g}$ & 60 & 69 & -14 \\
$\mathrm{SO}_{\mathbf{4}}$ & 19 & 16.5 & 13 \\
$\mathbf{K}$ & 43 & 41.5 & 3 \\
$\mathbf{C l}$ & 4600 & 4240 & 8 \\
\hline
\end{tabular}

The Beaker Method has been shown to successfully remove salts from higher dissolved solids hydraulic fracturing waters, but this water was too dilute. The intent was to lower TDS to 50,000 $\mathrm{mg} / \mathrm{L}$. This water started at 10,000 mg/L TDS. Barium removal was consistent in all cases. The change in solvent polarity lowered the solubility, which is small even in water, and removed barium as the sulfate. Other ions were not removed. Some ions showed a negative removal. The final volume in all three treatments was less than the starting volume, hence some ions showed higher concentrations.

\section{Laboratory Verification of PDU}

Laboratory studies consisted of multiple filtration runs, with and without EC pretreatment, with the objectives to determine an acceptable combination of filter media and evaluate the impact of EC pretreatment on the filtrate. Actual Marcellus RFW samples were used for all tests.

The PDU consisted of the 2-gpm FilterSure multiple module, multi-media filtration unit as shown in Figure 4. The unit consisted of five sequential modules containing selected filter media. As configured here, the five modules are made up of two stacks, three in one stack and two in the other, all five operating sequentially. If the media are selected correctly, all five modules will load up with solids at the same rate, minimizing offline time for backwashing the modules. A rented laboratory-scale EC unit was used to pretreat water samples. 


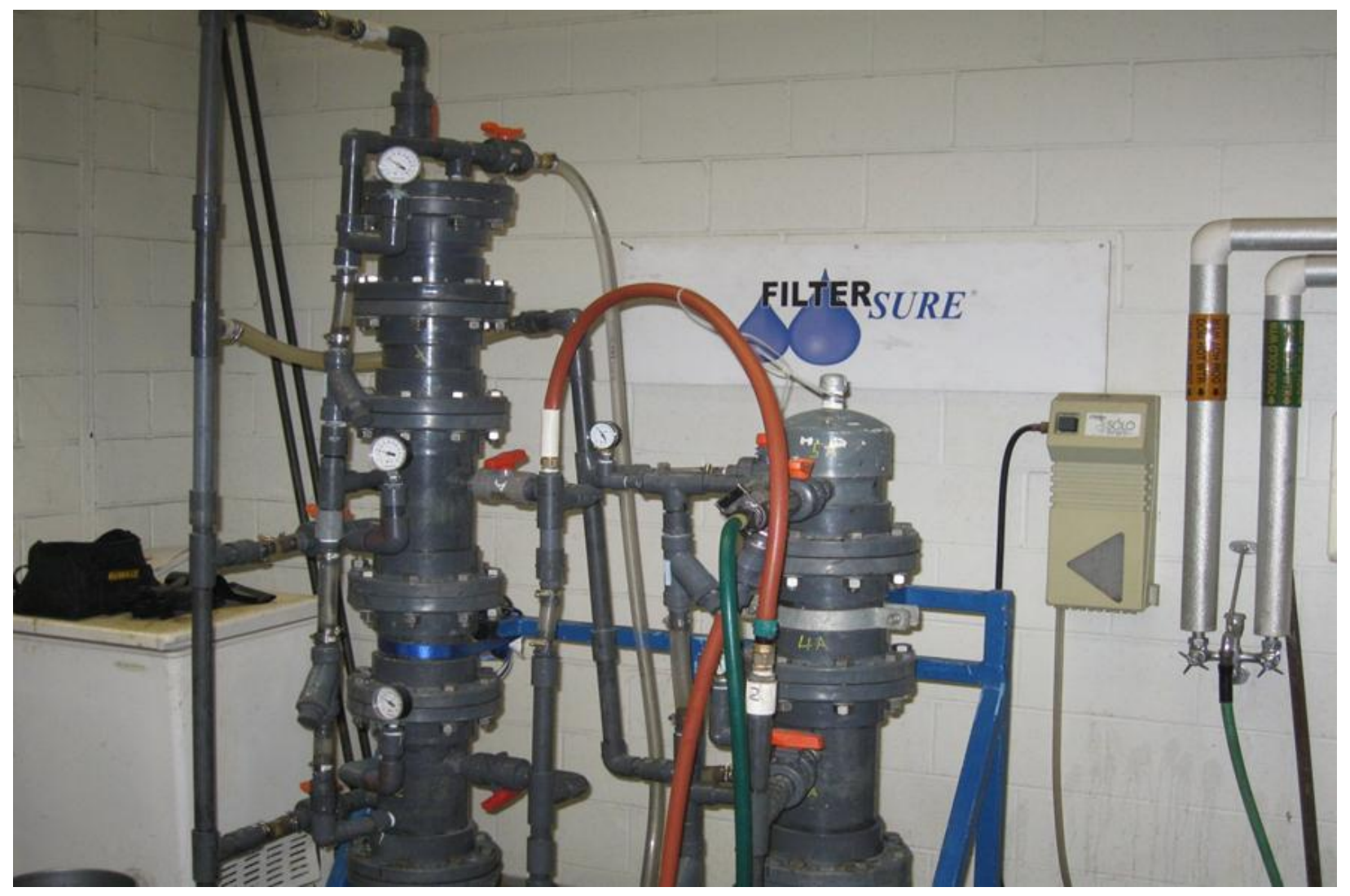

Once analyses were conducted on the raw RFW samples, each sample was divided into three sub-samples, one to be treated with EC only, one to be treated with the FilterSure filtration system, and one to be treated by the combination of EC plus FilterSure filtration. All samples were analyzed for natural salt constituents, TDS, TSS, hardness, $\mathrm{pH}$, and particle size distribution, both before and after each test. Results of tests were summarized in Table 8.

Results indicated significant reductions in divalent ion concentrations and TSS were reduced by up to $76 \%$ with retention of nearly $100 \%$ of particles larger than three microns. Therefore, the process design system proposed by the WVU project team and verified through analyses, consisting of the EC technology followed by the FilterSure filtration system, showed the capability to lower water hardness, reduce heavy metals to environmentally safe concentrations, and lower TDS values of RFW to be ready-for-use for the next hydraulic fracturing operation. 
Table 8: $\quad$ Summary of PDU and Laboratory Test Data

\begin{tabular}{|c|c|c|c|c|c|c|c|c|c|c|c|c|}
\hline & $\begin{array}{c}\text { A: } \\
\text { Raw }\end{array}$ & $\begin{array}{l}\text { A: } \\
\text { FS }\end{array}$ & $\begin{array}{c}\text { A: } \\
\text { EC* }\end{array}$ & $\begin{array}{c}\text { A: } \\
\text { EC+FS }\end{array}$ & $\begin{array}{c}\text { B: } \\
\text { Raw }\end{array}$ & $\begin{array}{l}\text { B: } \\
\text { FS }\end{array}$ & $\begin{array}{c}\text { B: } \\
\text { EC* }\end{array}$ & $\begin{array}{c}B: \\
E C+F S\end{array}$ & $\begin{array}{c}\text { C: } \\
\text { Raw }\end{array}$ & $\begin{array}{l}\text { C: } \\
\text { FS }\end{array}$ & $\begin{array}{c}\text { C: } \\
\text { EC* }\end{array}$ & $\begin{array}{c}C: \\
E C+F S\end{array}$ \\
\hline pH & 7.4 & 7.7 & 7.4 & 7.9 & 5.3 & 6.3 & 5.7 & 6.0 & 5.5 & 5.0 & 5.9 & 5.5 \\
\hline Cond & 66300 & 51000 & 61500 & 48800 & 183000 & 148000 & 182000 & 182000 & 194000 & 195000 & 326000 & 200000 \\
\hline $\mathrm{SO}_{4}$ & 28 & 11 & 21 & 13 & 414 & 101 & 131 & 88 & 73 & - & - & - \\
\hline $\mathrm{Fe}$ & 32 & 15 & 0 & 0 & 6 & 8 & - & - & 40 & 45 & - & - \\
\hline $\mathrm{Ca}$ & 1610 & 1540 & 1870 & 1040 & 10600 & 7830 & 9160 & 8820 & 21000 & 19300 & 20400 & 14600 \\
\hline Mg & 188 & 175 & 196 & 121 & 1200 & 786 & 978 & 933 & 2220 & 2270 & 2050 & 1120 \\
\hline $\mathrm{Na}$ & 8530 & 7260 & 9050 & 4960 & 32800 & 19500 & 21800 & 22600 & 45400 & 34400 & 42500 & 31100 \\
\hline K & 243 & 297 & 213 & 207 & 444 & 996 & 434 & 347 & 701 & 601 & 535 & 595 \\
\hline $\mathrm{Sr}$ & 280 & 249 & 334 & 214 & 1340 & 1090 & 1110 & 1250 & 2980 & 3120 & 3110 & 3090 \\
\hline $\mathrm{Ba}$ & 172 & 165 & 128 & 71 & 201 & 93 & 142 & 120 & 1440 & 1520 & 1390 & 741 \\
\hline $\mathrm{Cl}$ & 17100 & 13000 & 14800 & 12600 & 65000 & 51000 & 61800 & 62400 & 80400 & 95400 & 64400 & 89600 \\
\hline TSS & 99 & 81 & 5010 & 66 & 570 & 187 & 1050 & 138 & 882 & 681 & 112 & 302 \\
\hline TDS & 38700 & 28200 & 35000 & 26800 & 112000 & 81400 & 95600 & 96500 & 188000 & 187000 & 210000 & 166000 \\
\hline $\begin{array}{l}\text { Hard- } \\
\text { ness }\end{array}$ & 4890 & 4650 & 5620 & 3960 & 38000 & 22000 & 28900 & 25200 & 63400 & 74100 & 66000 & 42200 \\
\hline O\&G & nd & nd & nd & nd & nd & nd & nd & nd & 13 & nd & nd & nd \\
\hline
\end{tabular}

FS = FilterSure; $\mathrm{EC}=$ electro-coagulation; Cond = Conductivity

*EC technology provider considers the EC values to be misleading since lab tests can yield values for dissolved solids that include suspended solids. Provider filters their water with a 10-micron absolute filter to remove suspended solids before analyzing for solutes.

Based on the laboratory studies and the preliminary analysis of various treatment options, taking into account costs and their capabilities to potentially treat RFW, the WVU project team determined to further evaluate the use of filtration coupled with EC. A conceptual process train was developed to include the EC unit preceding the multiple module, multi-media filtration unit provided by FilterSure. The upstream component, the EC unit, would pretreat the RFW to enhance the filtration efficiency of the FilterSure system. The EC converts some of the dissolved solids to suspended solids, by chemical or electro-chemical means. Early testing demonstrated the capability to remove up to $99 \%$ suspended solids and reduced certain important dissolved solids; therefore, the need for subsequent processing to reduce TDS did not appear to be necessary based on industry experience with recycling of RFW at that time.

The FilterSure filtration system had proved itself under a number of water treatment scenarios; however, performance treating RFW and its unique water chemistry was unknown. Three samples of RFW obtained had TDS values ranging from 10,000 to upwards of 188,000 mg/L. Radioactivity was determined to be at or below background levels and total hardness ranged from 5,000 to nearly 64,000 mg/L. Particle Size Distribution (PSD) analyses were performed on the RFW samples prior to and after filtration, and before and after EC. Figure 5 shows PSD results of a RFW sample. A second RFW sample was treated by the EC unit followed by the FilterSure filtration system. As shown in Figure 6, this non-optimized EC test verified that EC was effective in coagulating many small particles to create much larger, easily filtered particles. All small particles, less than approximately 8-microns, were converted to larger particles ranging 
from about 10- to 200-microns, making them relatively easy targets for removal by the FilterSure filtration system.

Figure 5: $\quad$ PSD Before and After FilterSure Filtration of a RFW Sample

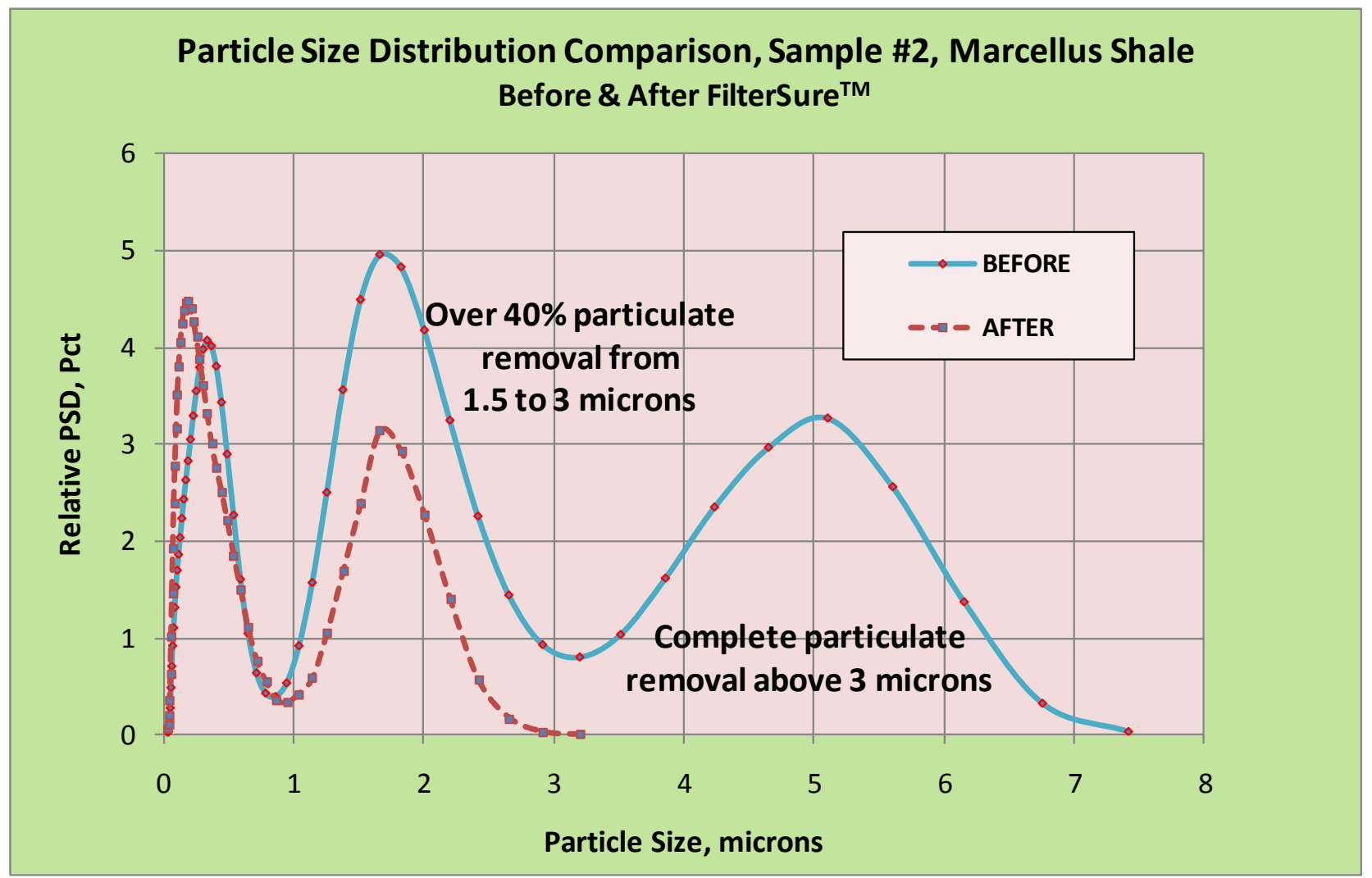


Figure 6: Particle Size in Raw and EC-Treated Marcellus RFW

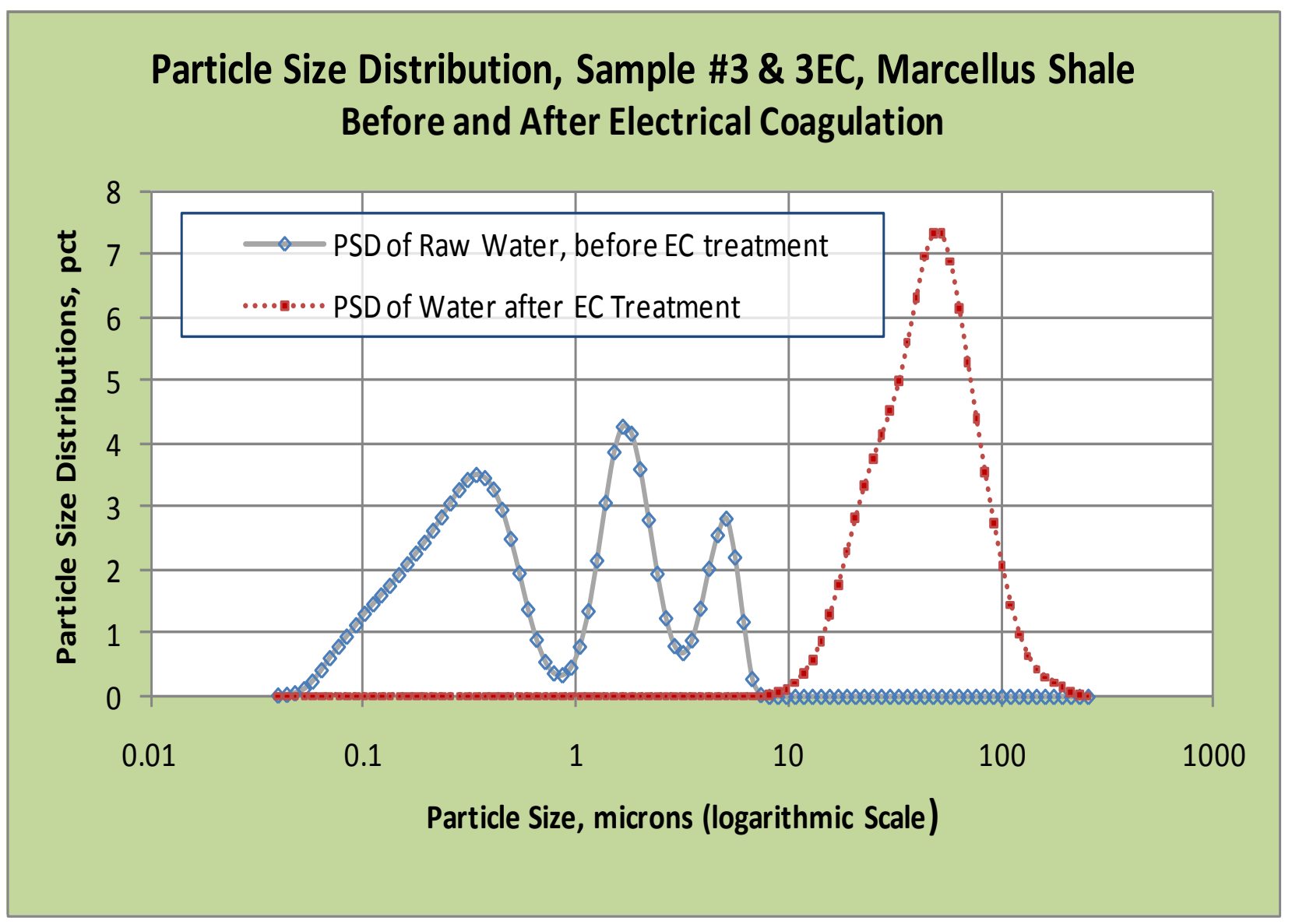




\section{Filtration without Pretreatment}

Members of the WVU project team met with members of the Industry Contact Group and toured active well development sites in Pennsylvania and West Virginia. The purpose of these meetings and site visits was to confirm current water management practices being implemented in the field and determine how this project might impact industry practices.

From the information obtained during these meetings and site visits, it was clear that large Marcellus Shale operators were not chemically treating their RFW prior to recycling. If they were treating the RFW, the treatment choice was 20-micron sized bag filters. Water treatment options were expected to have minimal operation and maintenance requirements and consist of a small, modular footprint. The operators indicated a desire for further dissolved metallic solids reduction and sulfates reduction; however, the removal of barium and strontium was no longer considered critical. Some of the producers injected untreated RFW, ignoring ideal design criteria established by the hydraulic fracturing support companies.

As a result of this industry input, it became clear to the WVU project team, major producers did not want or need the addition of EC or chemical flocculation prior to filtration as part of their RFW treatment system for recycling purposes. Although the companies indicated a desire for heavy metals removal, they were not interested in anything that might slow down or complicate fracking operations, including large equipment on their "always too small" well sites. Industry demonstrated their primary needs were high-rate filtration operations, a minimum of $100 \mathrm{gpm}$ and preferably much higher, while achieving suspended solids removal down to 20 microns. A reduction in sulfates was also considered important because of its capacity to form scaling compounds when the RFW would be recycled for new fracking operations. Additionally, the treatment system would need minimal operator support and maintenance, occupy a small footprint, and be easily mobilized and de-mobilized from site to site.

At the same time these activities were ongoing, the WVU project team was investigating the requirements for a full-scale EC unit to pair with the FilterSure system. It was becoming apparent that the EC unit would be more cumbersome than originally envisioned, require its own mobile trailer unit and large source of power, and would cost more to obtain and operate; not entirely insurmountable problems but worth further investigation.

The use of the multi-media FilterSure filtration system without EC pretreatment would provide better mobility requiring only one mobile trailer unit, lower capital and operating costs, and flexibility to meet throughput needs while meeting industry water treatment requirements for recycling RFW. Therefore, the WVU project team concluded: 
- FilterSure's multiple module, multi-media filtration unit met industry needs and offered a desirable level of environmental protection, and

- EC treatment was not a viable industry option for mobile treatment of Marcellus RFW, with on-site recycling as the end objective. Rather, EC was more suited for use at a stationary treatment facility where water would be brought to the facility for treatment. An EC unit that would be able to adequately handle the throughput needs of industry would require a much larger footprint and source of power, two characteristics that are not conducive or available to a Marcellus well site environment.

The WVU project team briefed DOE on the two viable options to move the project forward into the design, construction and field deployment phase:

1. Construct the EC and FilterSure mobile unit having a combined rated capacity of 30-gpm with a provision for by-passing the EC unit. This configuration would require two mobile trailer units, one for the EC unit and its separate power generator and one for all other components. The 30-gpm size was determined to be the largest-sized EC unit to keep the footprint and power requirements manageable for on-site applications. However, industry throughput requirements would not be met, or

2. Construct a mobile unit using only the FilterSure multiple module, multi-media filtration technology providing a throughput capacity of 120-gpm with the possibility to approach 150-gpm, while meeting minimum RFW treatment requirements. This configuration would require one mobile trailer unit for all components and power supply would be provided by a generator packaged with the mobile unit.

After further evaluation, along with input from the DOE, option two was subsequently approved. The design of the prototype Mobile Treatment Unit (MTU) would consist of two FilterSure multiple module, multi-media filtration units to provide the throughput capacity and minimum treatment requirements needed by industry for on-site treatment of RFW.

Opting for filtration without EC or other chemical pretreatment was expected to result in little or no reduction in dissolved solids. Because RFW typically consist of high concentrations of various natural salts, the question arose among some Marcellus operators if salt concentrations could reach a level that would deem the continued use of recycled RFW as part of the make-up of hydraulic fracturing water detrimental to well production. Analysis showed recycled RFW could be reused indefinitely. The process of combining fresh water with the saltier RFW resulted in a predictable but quickly-stabilized build-up of salt concentrations in the hydraulic fracturing water with successive blending cycles of RFW and fresh water.

For a given development region, the saltiness of water mixtures used for any subsequent hydraulic fracturing operation should quickly reach a maximum. This maximum value is a 
function of the amount of RFW available for blending and its initial salt concentrations. This stabilization, or maximum salt concentration, occurs by the $3^{\text {rd }}$ repeat cycle as shown in Figure 7 and Table 9. The salt concentration is approximately the same for the $4^{\text {th }}$ hydraulic fracturing cycle as for the $3^{\text {rd }}$ cycle, and will remain constant for all subsequent hydraulic fracturing operations, assuming no effective changes in significant variables from well to well.

\section{Figure 7: $\quad$ Predicting Stabilized Frac Water TDS when Recycling RFW}

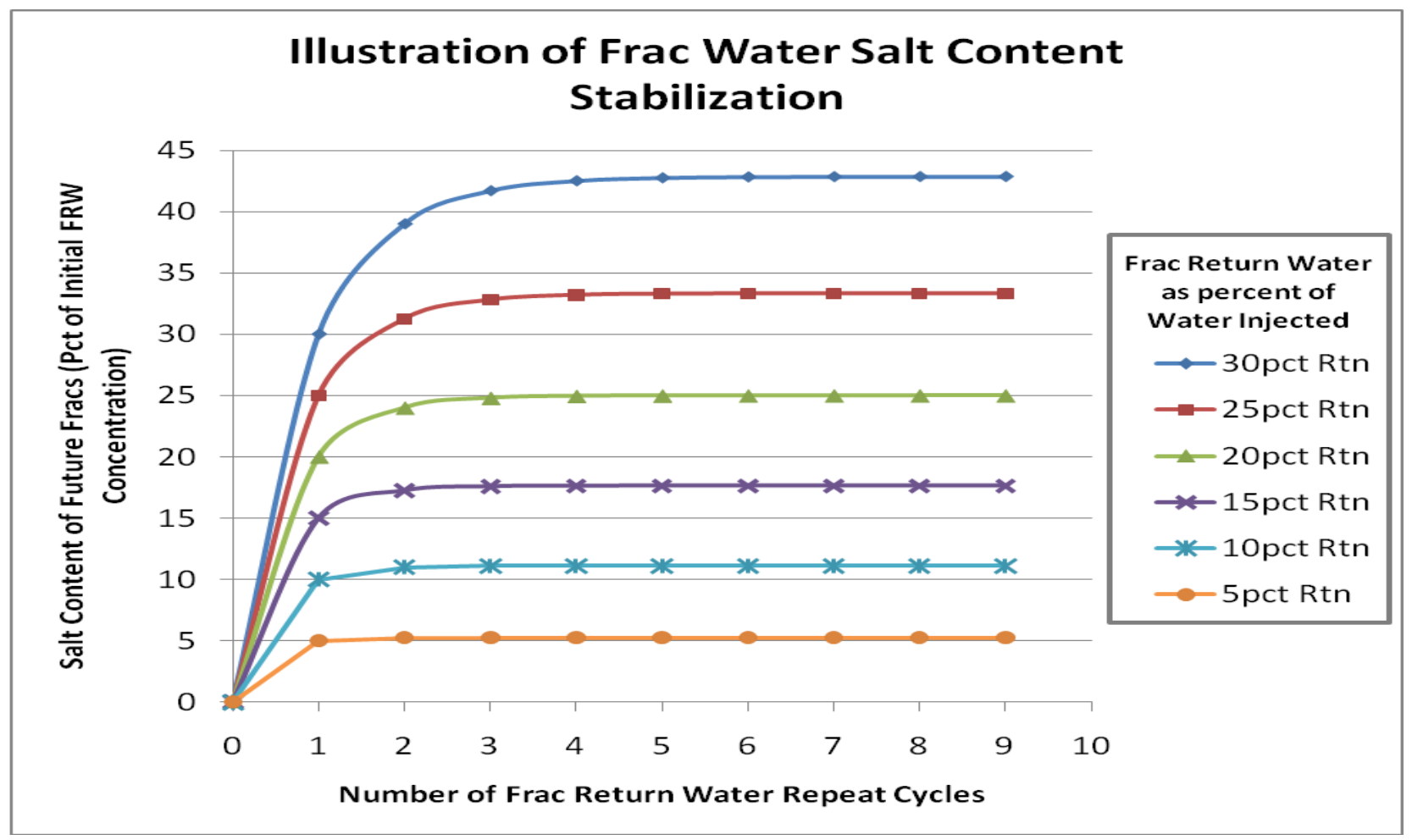

Table 9 provides a snapshot of the spreadsheet developed to calculate major ions and TDS concentrations of RFW recycled for subsequent fracturing operations. These values are based on the percent RFW recycled and blended with make-up water and initial water quality characteristics of both the make-up water and RFW. The user of Table 9 inputs the percent recycle rate along with initial water quality characteristics for the make-up water and RFW. Results of chemical analyses of the make-up water source and the RFW being used are entered into the spreadsheet. Values for TDS and the various ions listed are then calculated for each repeat cycle. For example, if the typical amount of RFW is $20 \%$ of the total amount of frac water injected, and the TDS of the RFW is $108,665 \mathrm{mg} / \mathrm{L}$, the stabilized salt concentration, TDS, for future hydraulic fracturing jobs will be approximately $27,366 \mathrm{mg} / \mathrm{L}$. Levels of the ions barium $(\mathrm{Ba})$, strontium $(\mathrm{Sr})$ and sulfate $\left(\mathrm{SO}_{4}\right)$ found in the $\mathrm{RFW}$, may be limiting factors for how much RFW can be blended with fresh make-up water for subsequent fracturing operations. 


\section{Table 9: $\quad$ RFW Dilution Model}

\begin{tabular}{|c|c|c|c|c|c|c|c|c|c|c|c|c|c|}
\hline \multicolumn{14}{|c|}{ RFW dilution model: all ions } \\
\hline recycle & & & & & & & & & & & & & \\
\hline rate & \multicolumn{2}{|c|}{ initial } & RFW & \multicolumn{10}{|c|}{ cycle } \\
\hline $20 \%$ & RFW & makeup & Maximum* & 1 & 2 & 3 & 4 & 5 & 6 & 7 & 8 & 9 & 10 \\
\hline TDS & 108,665 & 200 & 50,000 & 26,272 & 27,147 & 27,322 & 27,357 & 27,364 & 27,366 & 27,366 & 27,366 & 27,366 & 27,366 \\
\hline Hardness & 28,200 & 50 & 26,000 & 6,816 & 7,043 & 7,089 & 7,098 & 7,100 & 7,100 & 7,100 & 7,100 & 7,100 & 7,100 \\
\hline $\mathrm{HCO}$ & 100 & 20 & 300 & 43 & 45 & 45 & 45 & 45 & 45 & 45 & 45 & 45 & 45 \\
\hline SO4 & 50 & 60 & 50 & 70 & 72 & 72 & 72 & 72 & 72 & 72 & 72 & 72 & 72 \\
\hline $\mathrm{Cl}$ & 45,000 & 10 & 45,000 & 10,810 & 11,170 & 11,242 & 11,256 & 11,259 & 11,260 & 11,260 & 11,260 & 11,260 & 11,260 \\
\hline $\mathrm{Na}$ & 50,000 & 10 & 36,000 & 12,010 & 12,410 & 12,490 & 12,506 & 12,509 & 12,510 & 12,510 & 12,510 & 12,510 & 12,510 \\
\hline $\mathrm{Ca}$ & 8,000 & 20 & 8,000 & 1,939 & 2,004 & 2,017 & 2,019 & 2,020 & 2,020 & 2,020 & 2,020 & 2,020 & 2,020 \\
\hline $\mathrm{Mg}$ & 2,000 & 10 & 1,200 & 490 & 506 & 509 & 510 & 510 & 510 & 510 & 510 & 510 & 510 \\
\hline K & 500 & 15 & 1,000 & 134 & 139 & 140 & 140 & 140 & 140 & 140 & 140 & 140 & 140 \\
\hline $\mathrm{Fe}$ & 5 & 1 & 10 & 2 & 2 & 2 & 2 & 2 & 2 & 2 & 2 & 2 & 2 \\
\hline $\mathrm{Ba}$ & 800 & - & 10 & 192 & 198 & 200 & 200 & 200 & 200 & 200 & 200 & 200 & 200 \\
\hline $\mathrm{Sr}$ & 2,200 & - & 10 & 528 & 546 & 549 & 550 & 550 & 550 & 550 & 550 & 550 & 550 \\
\hline $\mathrm{Mn}$ & 10 & 1 & 10 & 3 & 3 & 3 & 3 & 3 & 3 & 3 & 3 & 3 & 3 \\
\hline
\end{tabular}

*From BJ Services FR and SI (Scaltrol 720)

\section{Phase II:}

\section{Mobile Treatment Unit Design, Construction and Operations}

With approval to move to the design and construction phase, two 60-gpm FilterSure commercial filters were selected for installation in a standard shipping container 40 feet long by 8 feet wide by 8 feet in height, mounted on a mobile chassis. Dual filter system controls provide automatic operation, maintenance operation, and monitoring of both filtration units. The system functions are controlled by a programmable logic controller (PLC) located in the control panel shown in Figure 8. The PLC interfaces with an operator interface Touchscreen (also referred to as an HMI - human machine interface), remote sensors and system devices. The HMI monitors and controls normal operation; system set-up such as timing, backwash settings and alarm settings; status and alarm conditions; and manual maintenance control. An operations manual along with instructions, drawings and schematics were placed inside the MTU for operator reference.

Designed to process up to 5,000 barrels/day, the mobile treatment unit (MTU), Figure 8, was customized for well-site applications providing a small footprint with an external generator for power $(50 \mathrm{kVA})$, easy movement between well pads, and quick set up for subsequent hydraulic fracturing activities. Once set up at a well pad site, the MTU will operate automatically requiring routine maintenance between fracturing treatments. 


\section{Figure 8: $\quad$ MTU General Arrangement}

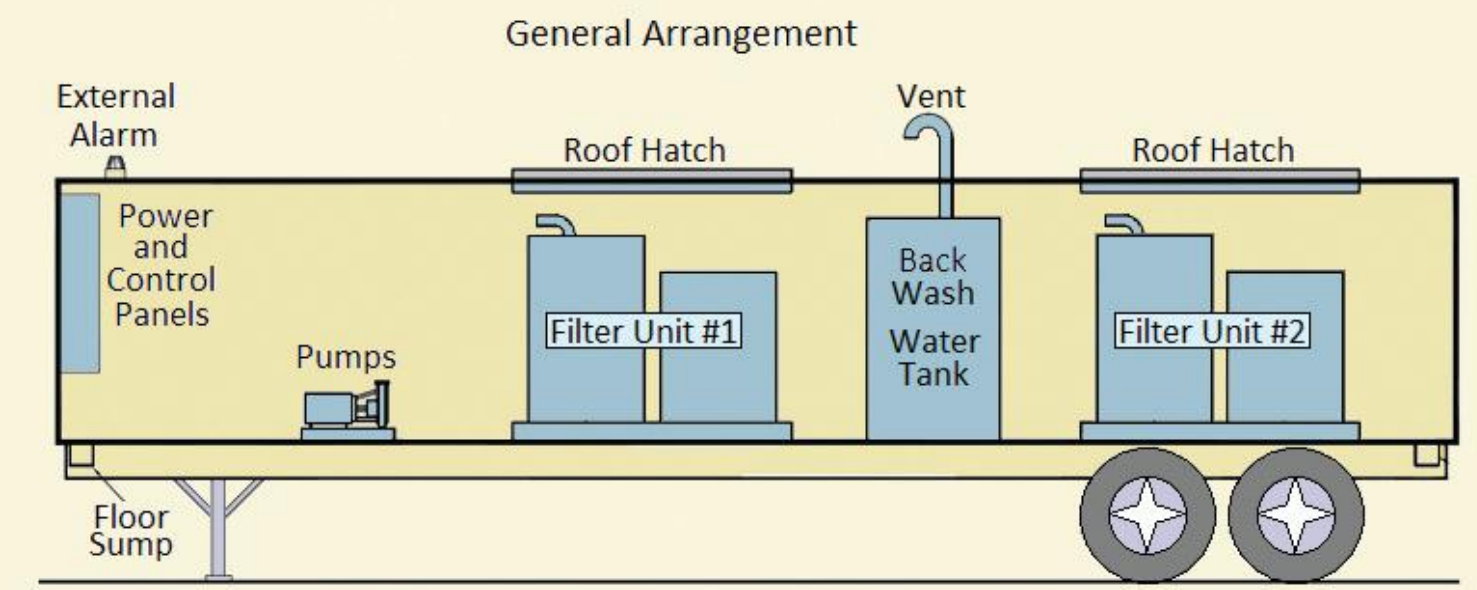

The flow of RFW through the mobile treatment unit is straightforward as detailed by the piping schematic in Figure 9. An in-line strainer is used to remove sticks and other large items that may be present in the RFW. The strained RFW then flows through two non-metallic centrifugal pumps. Flow meters are present prior to each filtration unit and sampling ports have been built into the treatment process prior to and after filtration. Each pump feeds one filter at a pressure of 80 pounds per square inch (psi) or less. The filters are designed with a media configuration capable of removing particles larger than three microns, making the filtered water suitable for recycling purposes. The filtered water exits the MTU and is ready for blending with fresh water for the next hydraulic fracturing operation.

Backwashing of a filter is determined by monitoring the pressure across each of the media modules and will occur on an as-needed basis, typically no more than twice each day, taking approximately 10 minutes for each backwash cycle per filtration unit (all five modules). Backwashing of the filtration units is staggered to maintain one filtration unit in operation at all times. Each filter unit is constructed to allow for one or all media modules to be taken off-line and backwashed. Captured solids are flushed using water stored in the backwash water tank (see Figures 8 and 9). These solids exit the MTU and are managed for disposal by the operator. The backwashed filter is returned to operation and the second filter is then taken off-line to be backwashed. Backwash water is returned to the beginning of the treatment process and mixed with incoming RFW for treatment. However, the piping configuration for entering and exiting the MTU allows for flexibility in managing the backwash water. 
Figure 9: Mobile Treatment Unit Piping Schematic Diagram

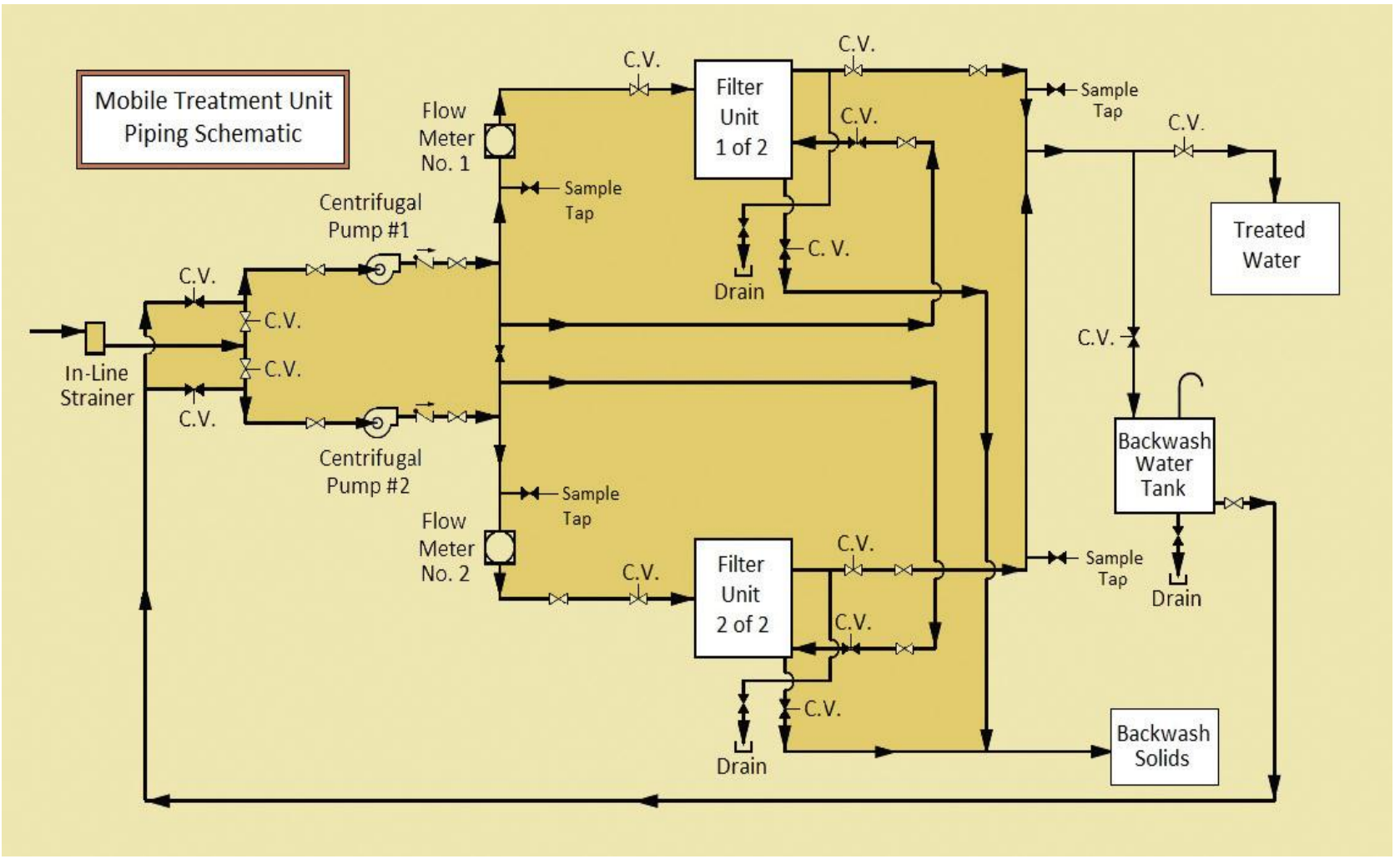

Construction of the MTU began in the spring of 2011 and proceeded without major issues. Figures 10 and Figure 11, exterior and interior photographs respectively, show progress near the end of the construction phase.

\section{Figure 10: Finished Exterior View of MTU}

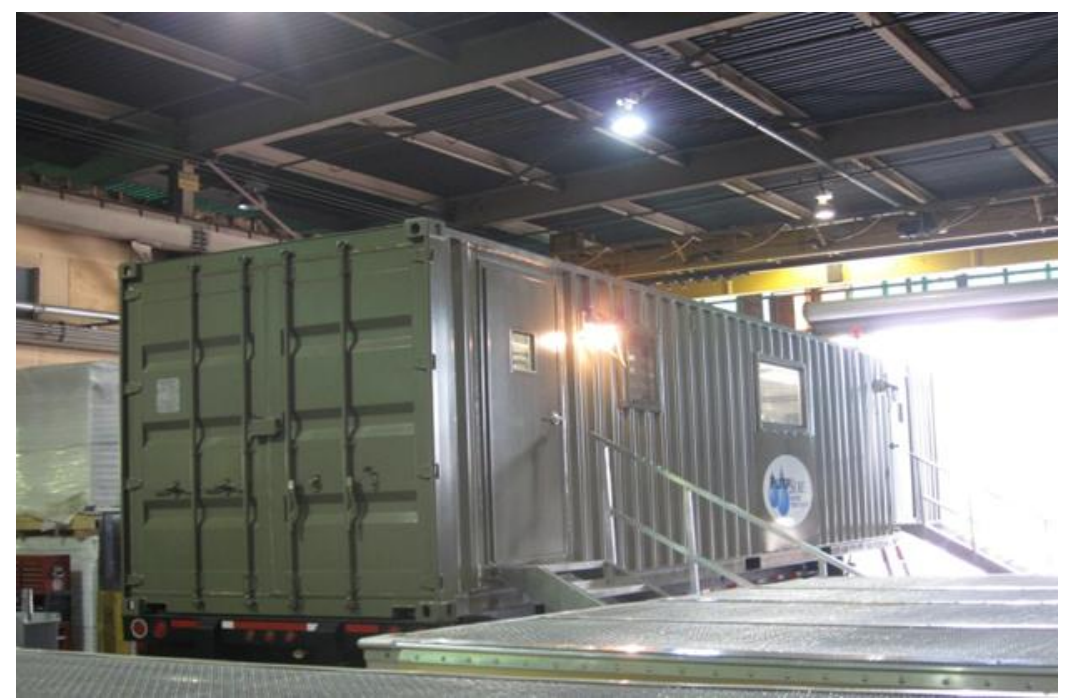




\section{Figure 11: Completed Interior View of MTU}

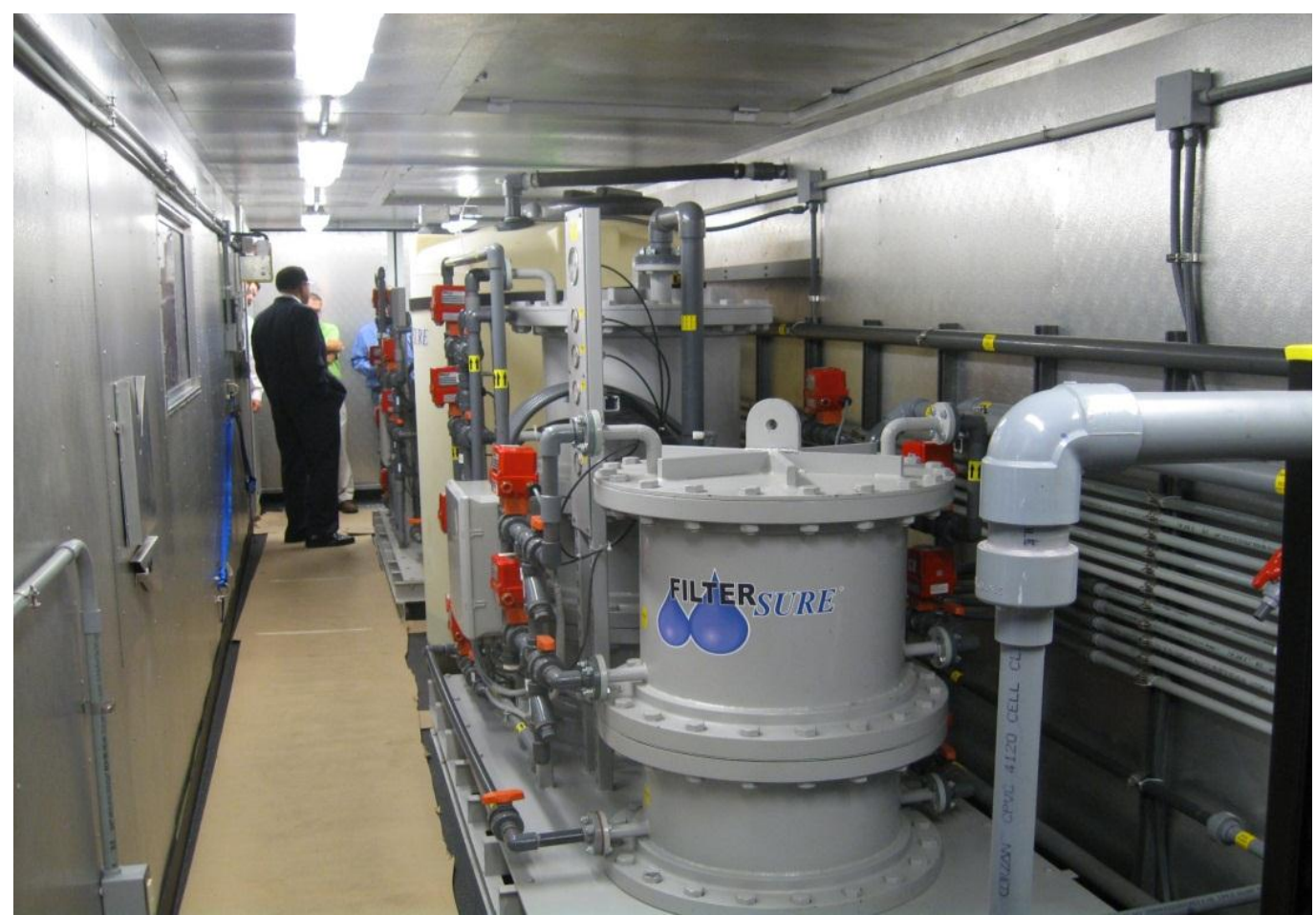

Selection of the final filter media to be used in the MTU was determined by additional laboratory testing using the FilterSure 2-gpm PDU. Nearly 100 barrels of Marcellus shale RFW were provided by a local operator for the additional laboratory tests. The RFW contained solids ranging in size from less than 3 microns to over 100 microns. Under high rate conditions, the PDU operating at rates up to 6-gpm, the media selected for the PDU removed particles larger than 3 microns as shown in Figure 12. 


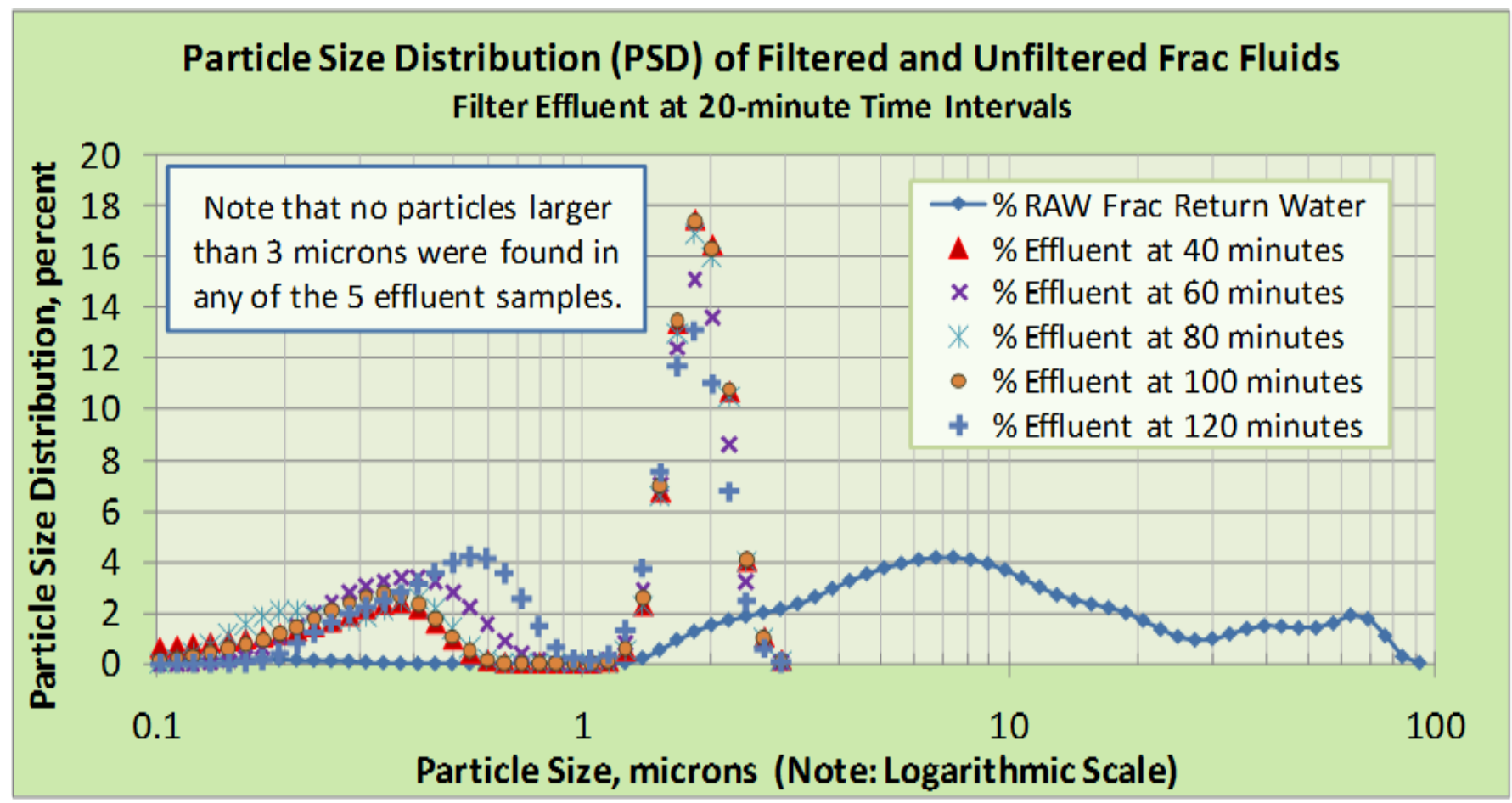

Over the course of the laboratory testing phase, the 2-gpm FilterSure PDU consistently removed solids and reduced various ions such as chlorides, sulfates, sodium and barium as summarized in Table 10. Chemically, the filtered RFW met the current industry standards for continued use as frac water when blended with fresh water. Therefore, the media and sequence tested in the 2gpm PDU was duplicated for both FilterSure filtration units installed in the MTU. Designed to process 5,000 barrels/day, the MTU was prepared for field deployment and real-time testing. 
Table 10: $\quad$ Filtration Results of Filtered RFW Samples

\begin{tabular}{|c|c|c|c|c|c|c|c|c|c|}
\hline & $\begin{array}{c}\text { A: } \\
\text { Raw }\end{array}$ & $\begin{array}{l}\text { A: } \\
\text { FS }\end{array}$ & $\begin{array}{c}\text { B: } \\
\text { Raw }\end{array}$ & $\begin{array}{l}\text { B: } \\
\text { FS }\end{array}$ & $\begin{array}{l}\text { C: } \\
\text { Raw }\end{array}$ & $\begin{array}{l}\text { C: } \\
\text { FS }\end{array}$ & $\begin{array}{l}\text { D: } \\
\text { Raw }\end{array}$ & $\begin{array}{l}\text { D: } \\
\text { FS }\end{array}$ & $\begin{array}{r}\text { Average } \\
\text { Change, } \\
\%\end{array}$ \\
\hline Cl & 17100 & 13000 & 65000 & 51000 & 80400 & 95400 & 150000 & 106667 & -14 \\
\hline $\mathrm{SO}_{4}$ & 28 & 11 & 414 & 101 & 73 & - & 0 & 0 & -69 \\
\hline $\mathrm{Fe}$ & 32 & 15 & 6 & 8 & 40 & 45 & 64 & 66 & 0 \\
\hline $\mathrm{Ca}$ & 1610 & 1540 & 10600 & 7830 & 21000 & 19300 & 21000 & 22183 & -8 \\
\hline Mg & 188 & 175 & 1200 & 786 & 2220 & 2270 & 2120 & 2187 & -9 \\
\hline $\mathrm{Na}$ & 8530 & 7260 & 32800 & 19500 & 45400 & 34400 & 42780 & 42780 & 20 \\
\hline K & 243 & 297 & 444 & 996 & 701 & 601 & 1810 & 1875 & 34 \\
\hline Sr & 280 & 249 & 1340 & 1090 & 2980 & 3120 & 5060 & 5267 & -5 \\
\hline $\mathrm{Ba}$ & 172 & 165 & 201 & 93 & 1440 & 1520 & 2290 & 2397 & -12 \\
\hline pH & 7.4 & 7.7 & 5.3 & 6.3 & 5.5 & 5.0 & - & - & 4 \\
\hline Cond & 66300 & 51000 & 183000 & 148000 & 194000 & 195000 & 197000 & 197167 & -10 \\
\hline TSS & 99 & 81 & 570 & 187 & 882 & 681 & 484 & 313 & -36 \\
\hline TDS & 38700 & 28200 & 11200 & 81400 & 188000 & 187000 & 187000 & 168667 & -16 \\
\hline Hardness & 4890 & 4650 & 38000 & 22000 & 63400 & 74100 & 65900 & 69300 & -6 \\
\hline $0 \& G$ & nd & nd & nd & nd & 13 & nd & nd & nd & \\
\hline $\begin{array}{l}\text { Charge } \\
\text { Balance, } \\
\text { \%diff }\end{array}$ & 0 & 14 & 13 & 6 & 38 & 3 & 25 & 11 & 14 \\
\hline
\end{tabular}

\section{Field Trials}

Two field trials were completed, both under a lease agreement with Chesapeake Energy (Chesapeake). The first location was a Utica Shale site in Carrollton, Ohio. The second was a Marcellus Shale site located near Wheeling, West Virginia.

\section{Site 1: $\quad$ Utica Shale Site}

FilterSure moved the MTU from the manufacturing location to the first drilling site located in Carroll County, Ohio. Storage containers were available on site to hold water prior to filtration and to provide storage after treatment prior to blending with fresh water for the next fracturing operation. At this particular site, storage containers were the preferred method of water storage 
instead of impoundments. Chesapeake positioned the MTU where untreated water from the yellow tanks shown in Figure 13 could be easily connected to the MTU. The filtered water was transferred to empty storage tanks located to the right of the MTU (not shown in this photograph). Filtered RFW was blended with fresh water and used in subsequent hydraulic fracturing operations.

\section{Figure 13: On Location at Utica Shale Site in Ohio}

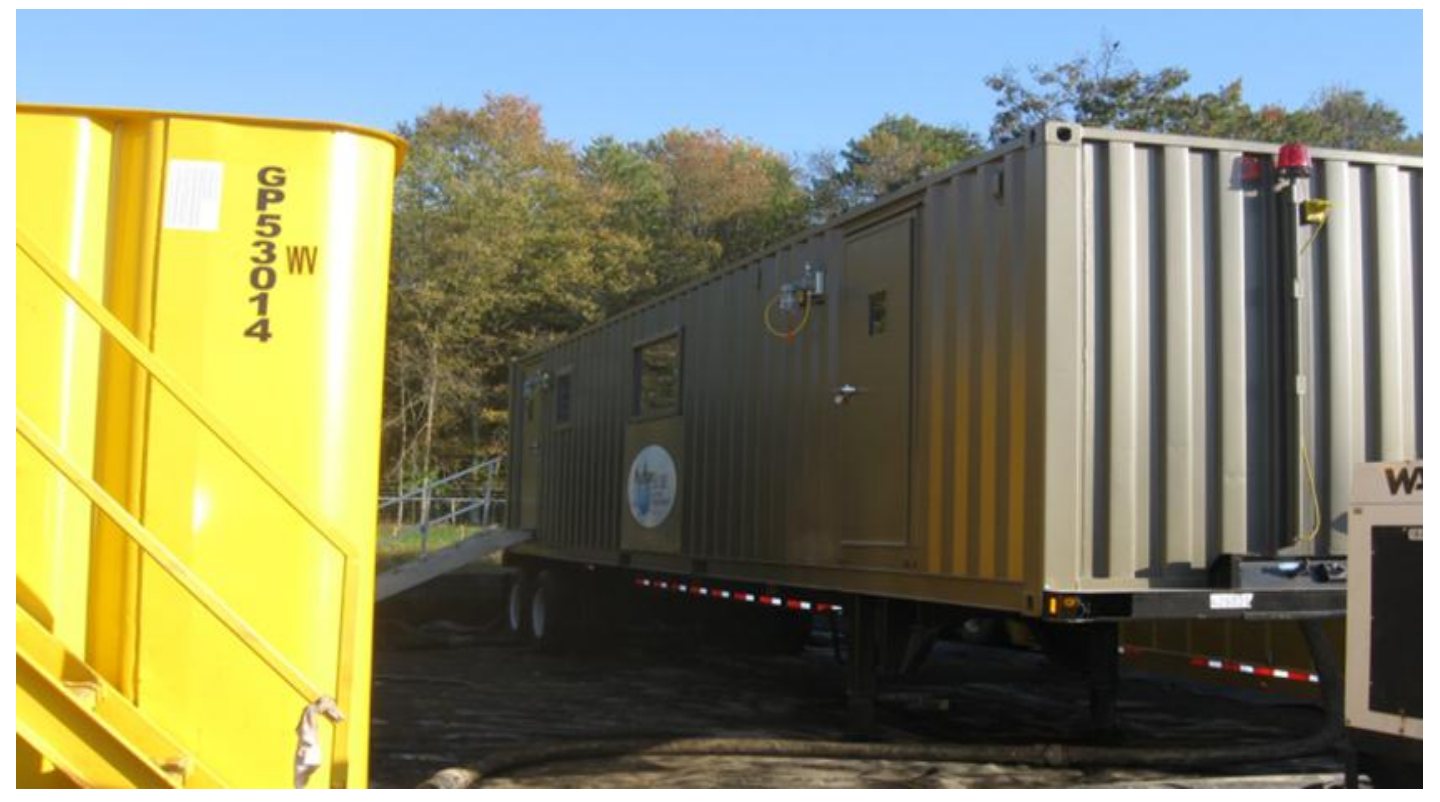

The MTU was on site in Carrollton, Ohio for eleven days, of which the unit was in "operational mode" nine days. Once the MTU was positioned by Chesapeake on the well pad, it was connected to the generator for power and connections were made to the water storage tanks supplying water to be treated and collecting water after treatment. Commands for the PLC were updated and initial testing of the system was conducted prior to start-up to ensure the alarm system and automatic shutdown mode executed properly. Emergency and safety systems were in place and worked according to the operations manual.

The Ohio site consisted of one well with 15 fracking stages. The company on site overseeing the fracturing operations performed two fracking stages per day. Water was collected from various Chesapeake development wells and trucked to the Ohio site to be treated by the MTU prior to blending with fresh water. These liquids ranged in quality from rain water to highly saline water. Some of the liquids also contained oils and polymers collected from recently fracked oil wells. In addition, as a part of its water management plan, Chesapeake routinely removed rain water trapped behind an extensive dyke system constructed for secondary containment of water that may leak from storage operations. This water was pumped into the "raw" water storage tanks to be treated by the MTU for recycling as well (yellow tanks shown in Figure 13). The quality of 
the water being processed through the MTU was unpredictable, it was a highly variable liquid that sometimes contained a significant quantity of oil and/or polymer, as seen in Figure 14. Although the oil and polymer mixture was processed (removed) by the MTU, it was at a cost of higher pressure and a reduced throughput rate.

\section{Figure 14: $\quad$ 0il/Polymer Mixture Treated by MTU}

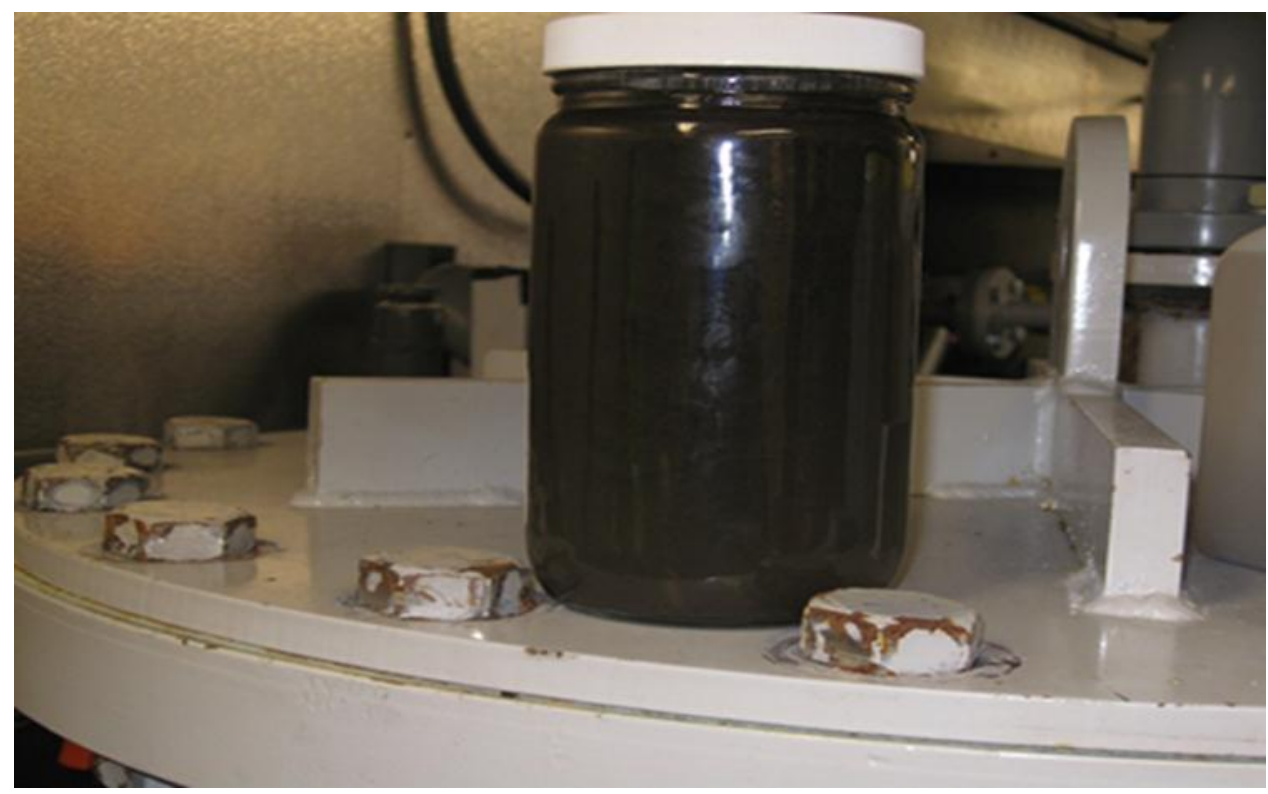

At the Carrollton, Ohio site, the MTU processed water for fracking at a rate of 122 gallons/min (about 4,000 barrels/day). Pressure across the filter modules remained relatively low, averaging around 30 psi. Water leaving the MTU was clear in appearance and influent and effluent samples were collected and processed for laboratory analysis. However, these samples were not considered to adequately represent the entire 200,000 gallons of water treated at the Ohio site because of the variation in water brought in to the site. The water chemistry was fairly consistent with other hydraulic fracturing water samples taken during this project for analysis. Also, filtration did not significantly change the water chemistry of the major ionic species.

The MTU is designed for automatic or manual operations. However, to meet Chesapeake's site safety guidelines, an MTU operator was on site while the unit was in operation. The panel mounted on the wall shown in the background of Figure 15, controls the MTU operations and records all operational conditions. Figure 16 is a photograph of the Touchscreen or HMI showing Filter 1 operating at $41 \mathrm{gpm}$ and Filter 2 operating at $43 \mathrm{gpm}$; thus, the total flow through the MTU at the time of the photograph was $84 \mathrm{gpm}$, or 2,880 barrels/day (bpd). 


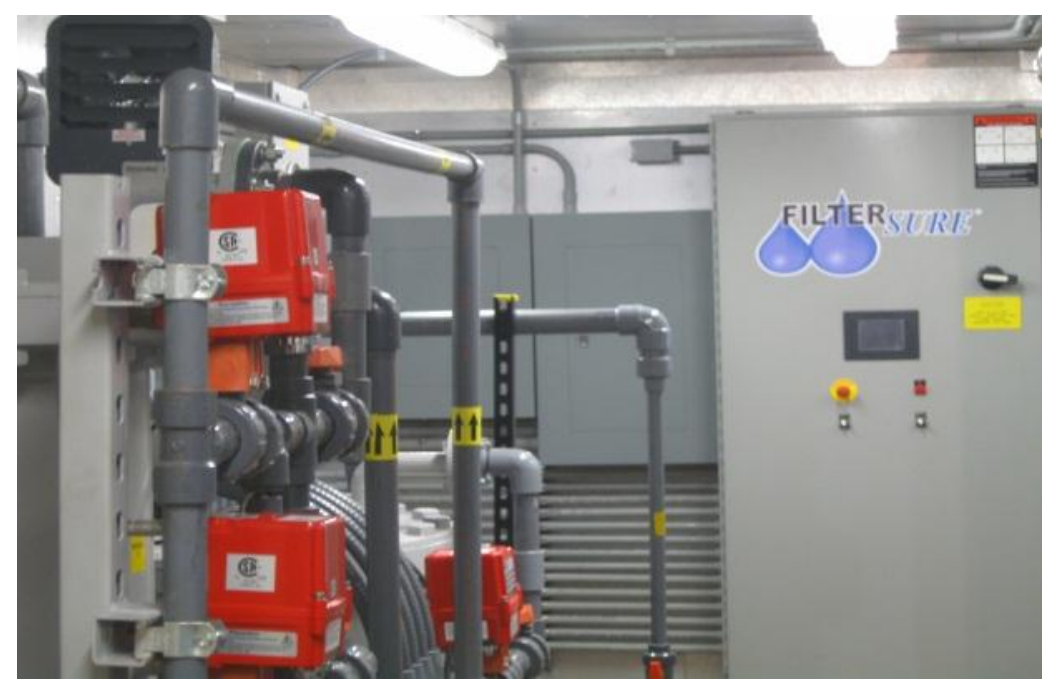

Figure 16: Control Panel Close-Up View

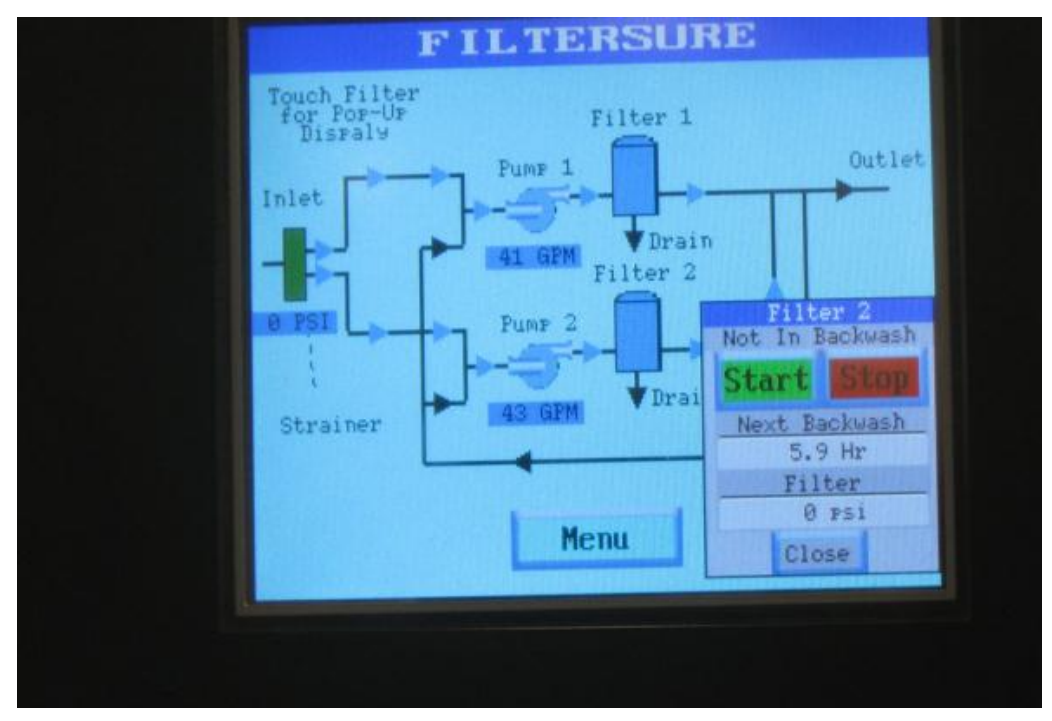

A pressure gauge records the pressure drop from the inlet to the outlet of each filter, Figure 17. At the time of this photograph, Figure 17, the pressure drop across Filter 1 was 64 psig and across Filter 2 was 68 psig. The pressure drop across each module monitors the performance of the media contained in each filtration cell (build-up of solids removed from the water), is used to adjust backwash cycles as needed and to modify selection of media for future applications based on the quality of water being treated by the MTU. 
Figure 17: Pressure Drop Measurements of MTU in Operation

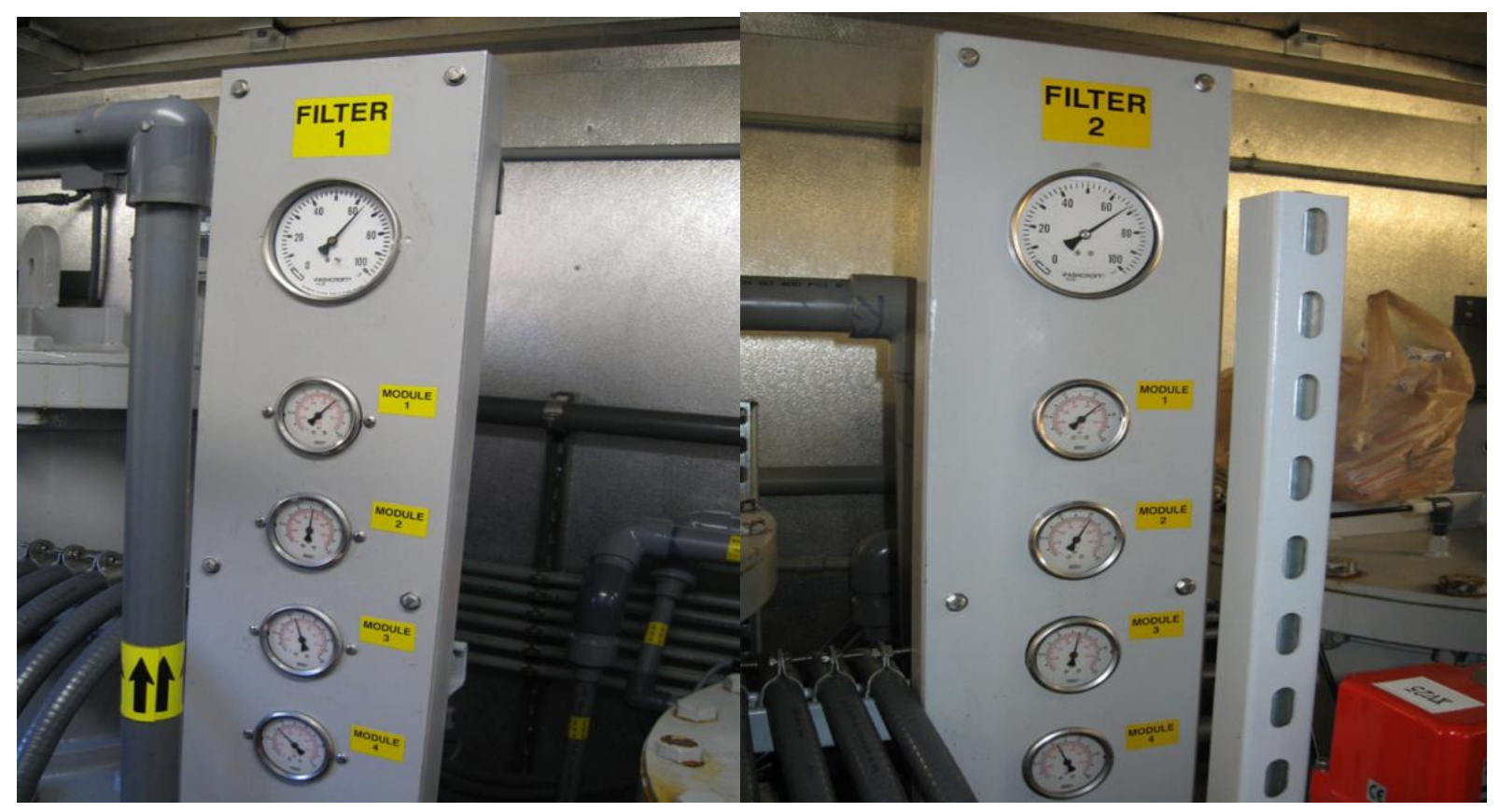

Initial operations showed a gradual decline in the throughput (filtration) rate and a gradual increase in pressure as the media collected solids and the system stabilized. Figure 18 plots the throughput rates and inlet pressures for the first six days of operation. On day one, the MTU began processing water at a throughput rate of $122 \mathrm{gpm}(4,183 \mathrm{bpd})$ and stabilized at a throughput rate of $104 \mathrm{gpm}$ (3,566 bpd) by day five. Over this period, the pressure increased from an initial pressure of $30 \mathrm{psig}$ to $53 \mathrm{psig}$. 
Figure 18: Day 1 through Day 6 Filtration Rates and Pressures

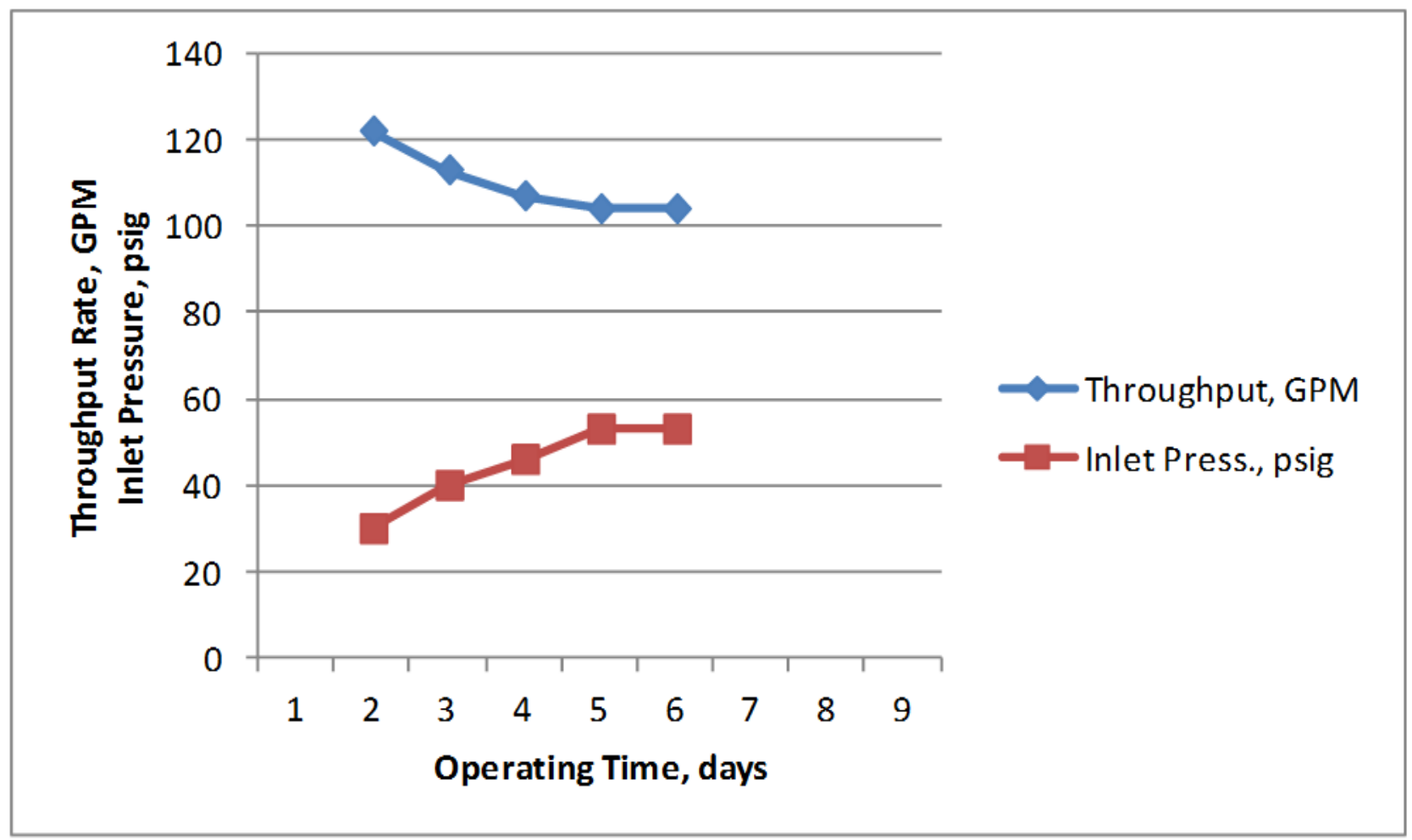

During day six of operations, processed water containing a high concentration of an oil and polymer mixture, as shown previously in Figure 14, was received and processed through the MTU. The impact of the heavy solids and oil/polymer loading on pressure and filtration rate is reflected in Figure 19. Pressure increased 32\%, from 53 psig to 70 psig. At the same time, the rate decreased 25\%, from $104 \mathrm{gpm}$ to $78 \mathrm{gpm}$. Most of the oil and polymer mixture was captured during the normal programmed backwash cycles; however, some of this mixture was retained on the filter media. By day eight, the backwash cycles had successfully removed the remaining mixture of oil and polymer with trapped solids on the filter media, increasing throughput from $78 \mathrm{gpm}$ to $84 \mathrm{gpm}$ while simultaneously lowering the pressure from $70 \mathrm{psig}$ to $66 \mathrm{psig}$. The backwash cleaning process returned operating conditions to a $100 \mathrm{gpm}$ throughput rate at an inlet pressure of approximately $45 \mathrm{psig}$ by the end of day nine. 
Figure 19: Filtration Rate and Pressure, Days 1 through 9

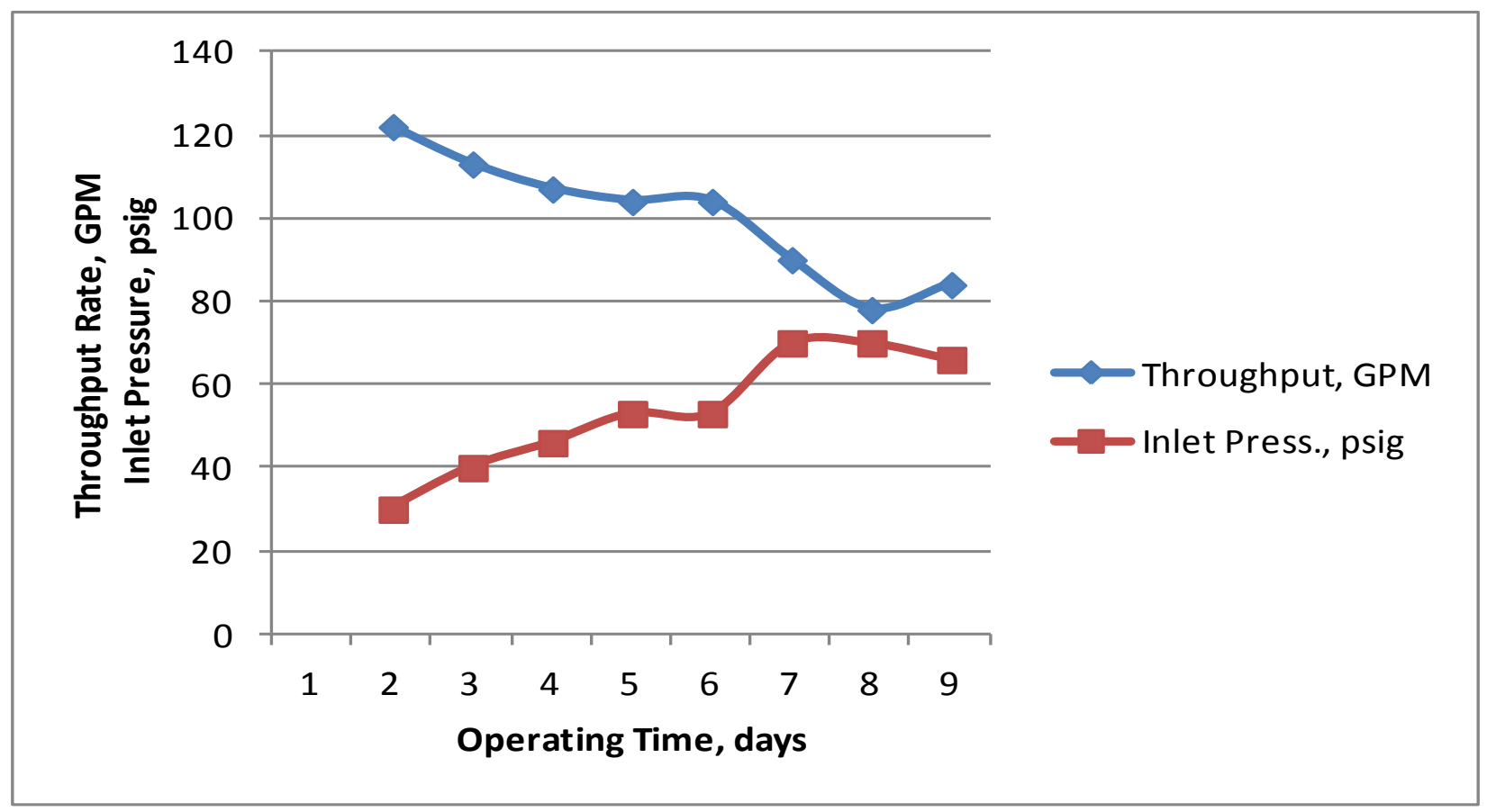

Backwash cycles were originally programmed to occur once every twelve hours of operation. Each module is backwashed individually for a period of two minutes, with a total backwash time lapse of ten minutes per filtration unit. Backwash cycles were set manually at the Carrollton, Ohio site until the MTU operators learned to manage the sporadic availability of RFW to process for recycling and system upsets caused by the unpredictable introduction of the oil and polymer mixture in the influent stream. Visual observation of the backwash water verified solids were being removed by the media. This initial field operation validated the extensive laboratory testing of the 2-gpm PDU conducted at West Virginia University (WVU). Media selected for the 2-gpm PDU were subjected to extended-run tests, leading to the selection of the media that were subsequently loaded into the MTU. No technical issues were encountered scaling from the 2-gpm PDU used in the WVU tests to the 120-gpm MTU.

At the Carrollton, Ohio site, trucks delivered water around the clock in preparation for the hydraulic fracturing operations. In addition to the MTU treating the water being received on site, a 10-micron bag filtration system was also on site as a second treatment option. The flow of water was split and sent to the MTU or bag filters for treatment. However, within minutes of receiving the water containing the oil and polymer mixture, the bag filters plugged and had to be taken off-line in order for the filters to be replaced. Processing of the water was slowed, reduced throughput, but the MTU operations continued without interruption, removing the oil/polymer mixture from the water and recapturing it through the backwash cycles. 
The MTU utilizing the FilterSure technology proved to be highly versatile responding to "upset" conditions. This response capability will continue to improve with future plans to introduce an additional media module that will capture oil-based solutions before passing through to the other media modules of the filtration unit.

\section{Lessons Learned from Site 1}

Laboratory tests using a consistent quality of produced water cannot match the variable quality and quantity of the water delivered to a site by hundreds of trucks supplying water from a wide variety of sources. Even so, laboratory tests conducted at WVU utilizing the 2-gpm PDU for processing various RFW samples resulted in the selection of five media types that treated the water for recycling purposes.

Media for the MTU needs to be more robust in its capability to capture oil and/or polymers before this mixture enters the lower modules of the filter. In the future, an oil-loving media will be used to process the influent before it enters the MTU or placed in the first of the five filtration modules used in the FilterSure technology. This approach will protect the lower modules from fouling, and greatly reduce the time to backwash the unit to restore overall throughput at a reasonable inlet pressure.

\section{Site 2: $\quad$ Marcellus Shale Site}

Upon completion of water treatment operations at the Carrollton, Ohio site, Chesapeake relocated the MTU to a location near Wheeling, West Virginia. Figure 20 shows the arrangement of water storage tanks and the MTU, the MTU is located in the left top corner of the photograph, on the well pad. RFW for filtration was trucked onto the site and stored in the tanks in the foreground as shown in Figure 20. From the storage tanks, the water was processed through the MTU. The filtered water was stored in the yellow tanks positioned to the right of the FilterSure unit and ready for blending with fresh water supplies prior to the hydraulic fracturing operations. 
Figure 20: $\quad$ Marcellus Shale Site, West Virginia

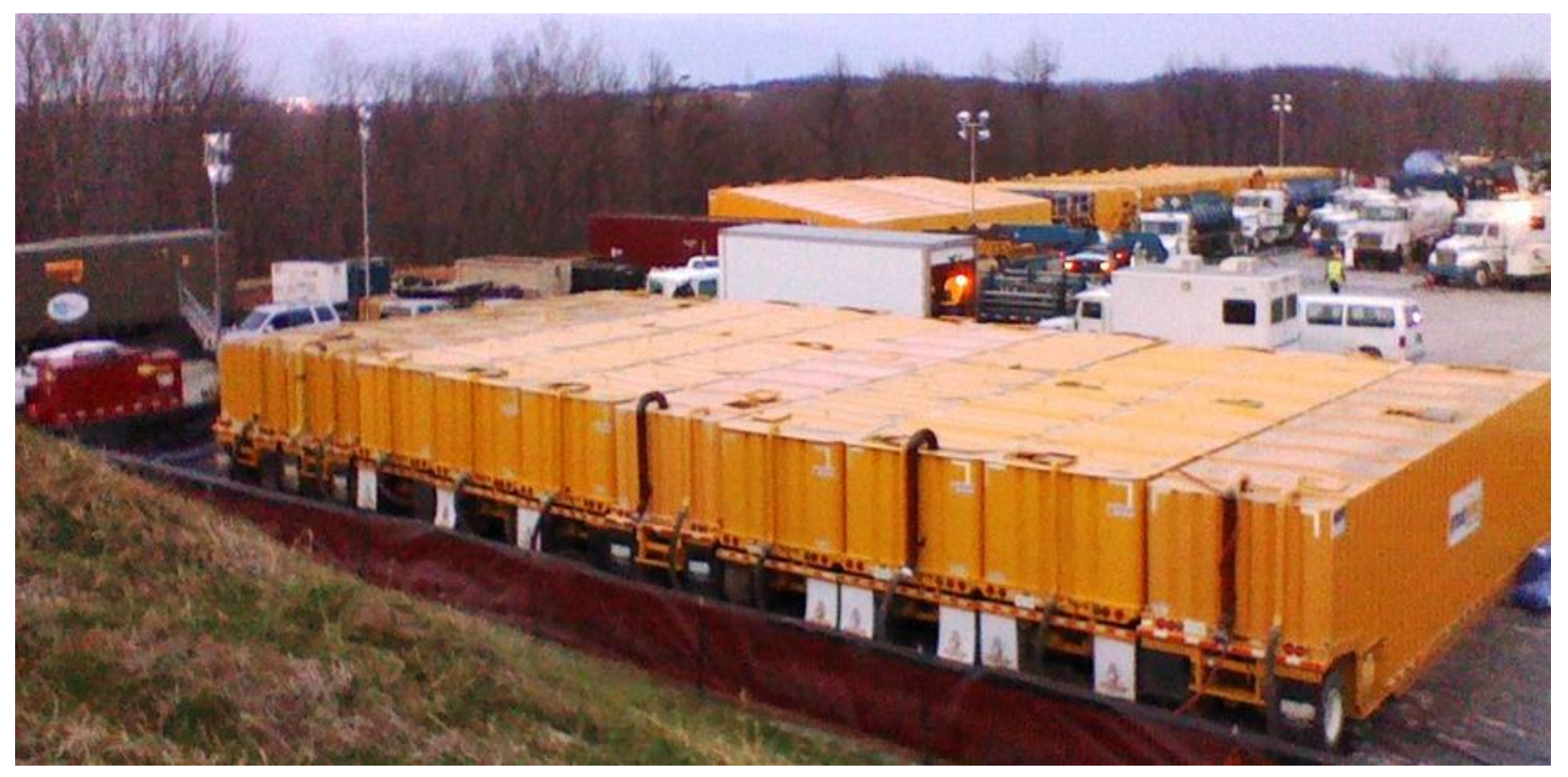

Upon arrival at the new site, the Dytko Site, in West Virginia, a series of system checks were performed and the MTU was prepared to begin operations. The MTU supported a nine-stage fracking operation, operating at an average filtration rate of $104 \mathrm{gpm}$ and at a pressure of $52 \mathrm{psig}$ to treat RFW prior to blending with fresh water supplies. Within four days, all stored RFW, approximately 147,000 gallons, was filtered and consumed the storage capacity provided for processed (treated) water ready for recycling. Once fracturing operations began, the MTU was taken off-line during the actual fracture operations while water was withdrawn from the filtered water tanks and blended with fresh water for use in fracturing. Filtration resumed after each fracture stage.

Figure 21 details the fracturing stages and the amount of RFW processed by the MTU. MTU operations were able to keep up with the ongoing demands to support the eight hydraulic fracturing stages. One additional fracture was supported but not shown in Figure 21 before fracture operations were completed. Nearly 288,000 gallons of water was processed by the MTU at the Dytko Site. 


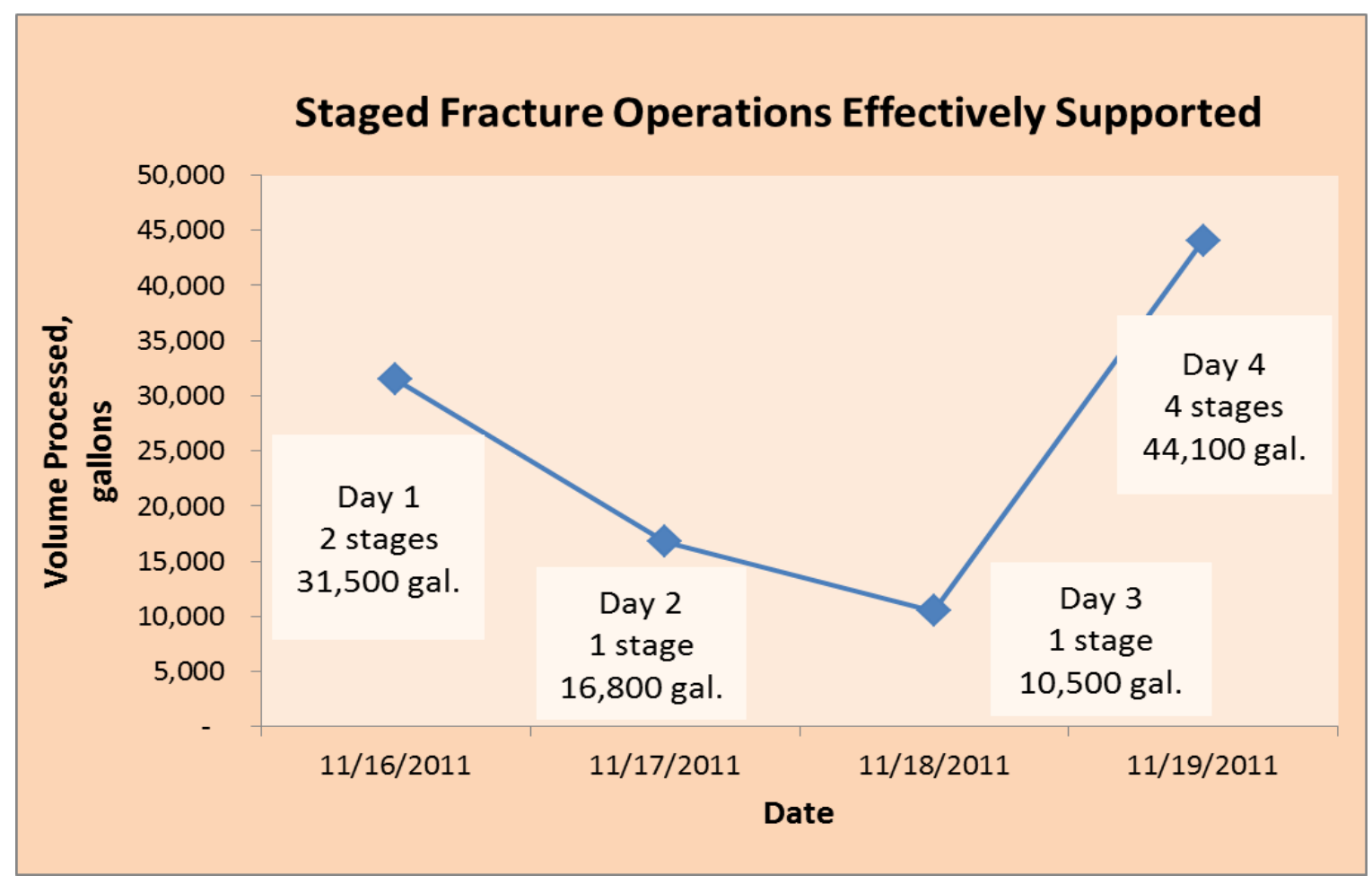

Frequent rate and pressure data were taken during the fracking operations. Figure 22 summarizes this data showing stable throughput (filtration) rates and pressures. Filtration rates averaged $104 \mathrm{gpm}$ at an average filter inlet pressure of $52 \mathrm{psig}$. There were no major deviations in the rate and pressure data, reflecting relatively clean water was being processed for recycle purposes. 


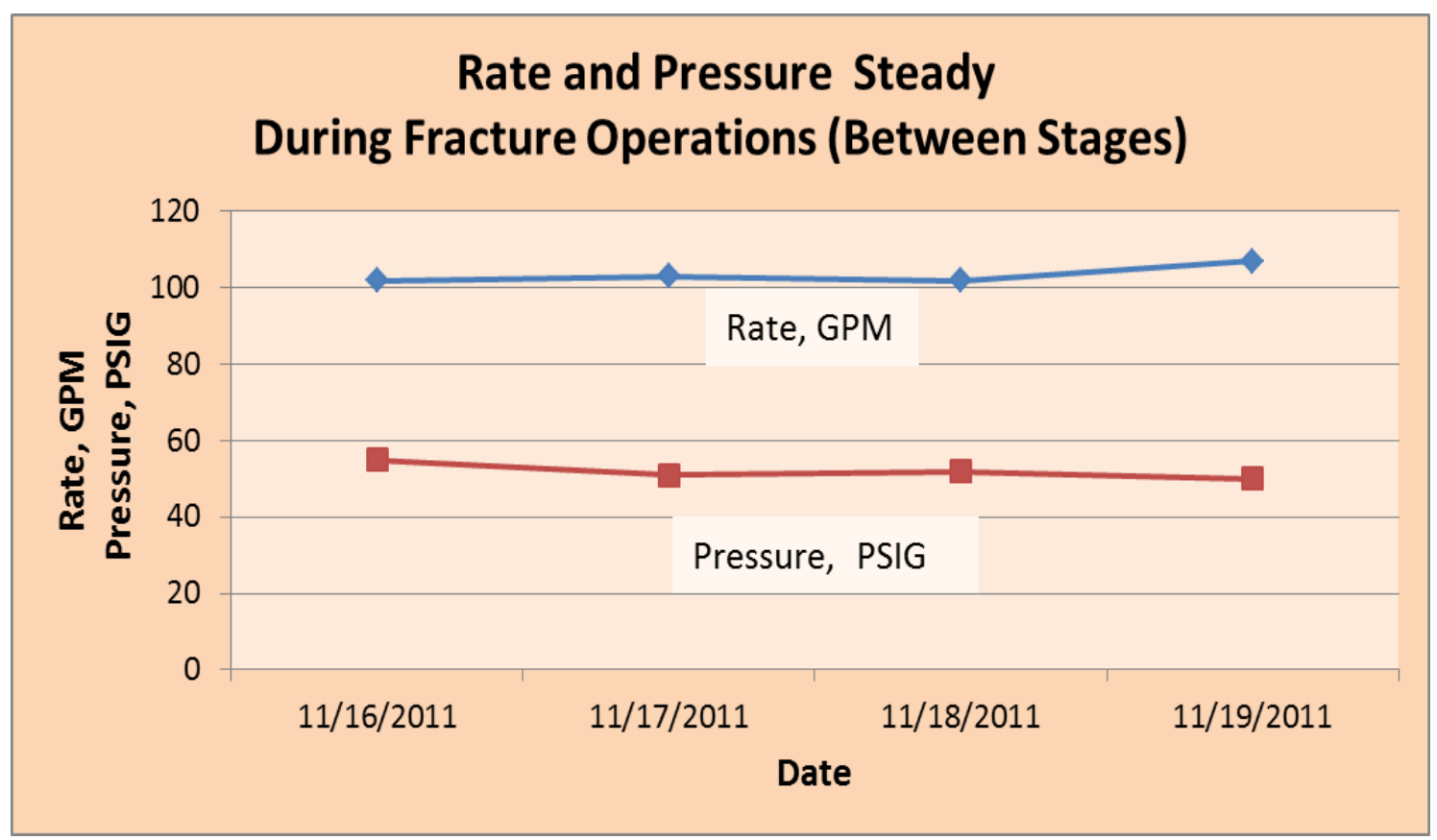

As mentioned previously, during active fracturing, the MTU was off-line. While off-line, captured solids were removed by backwashing each filter individually. Ten backwash cycles were completed using an average volume of 400 gallons per cycle. Backwash volume totaled 4,000 gallons. RFW processed for recycle totaled 288,000 gallons for blending with fresh water. Of the total volume of water sent through the MTU unit, $98.6 \%$ was recycled with $1.4 \%$ returned for disposal.

MTU operators learned from the Ohio site operations that water collected for physical and chemical analyses need to reflect a broad range of water influent and effluent. Accordingly, MTU operators collected composite samples over a period of time while at the Dytko Site. These composite samples were submitted for particle size distribution (PSD) to the Civil Engineering Department at WVU and for chemical analysis by REIC Laboratories located in Beaver, West Virginia.

Concentration of particles in the collected water was unexpected. All prior testing of Marcellus Shale RFW had particle size distributions ranging from near-zero to over 100 microns in size. However, both the influent and effluent water collected from the West Virginia site had particles that ranged from near-zero to less than three microns. Concentration of the influent and effluent particles is shown in Figure 23. 


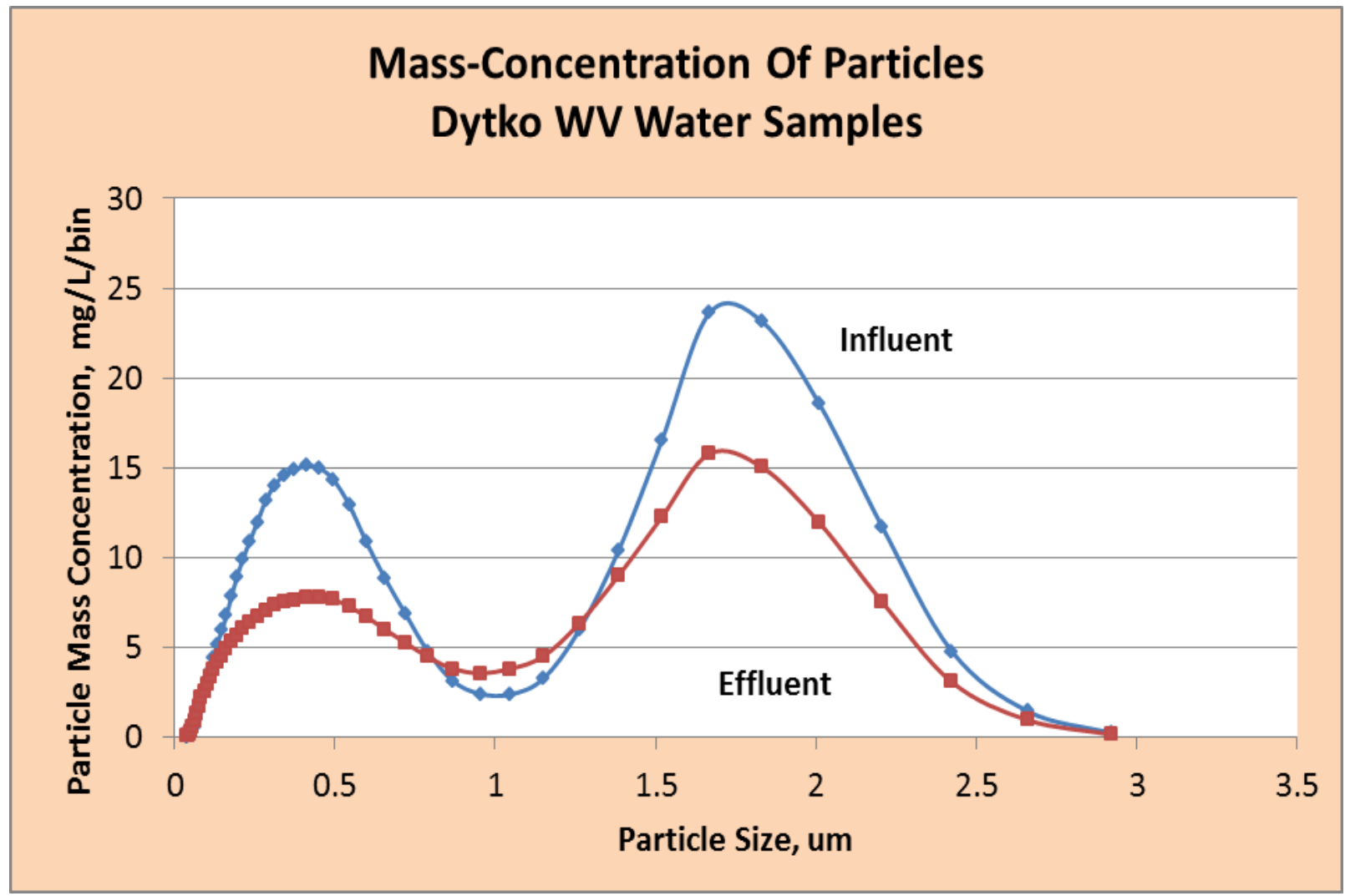

It is clear from Figure 23, particle size data the MTU did indeed remove particles that were as small as 0.5 microns in diameter. This is remarkable removal efficiency and is shown graphically as the difference between the blue (influent) and the red (effluent) curves of Figure 23. This reduction in volume shows up as a reduction in Total Suspended Solids (TSS) in the water chemistry analysis prepared by REIC laboratories.

Water chemistry analysis results are presented in Table 11. These results independently verify the MTU removed $32 \%$ of the suspended solids. Specifically, the TSS fell from $360 \mathrm{mg} / \mathrm{L}$ to $244 \mathrm{mg} / \mathrm{L}$, a reduction of $116 \mathrm{mg} / \mathrm{L}$. Previous controlled laboratory testing using Marcellus Shale RFW samples had an average TSS influent of $517 \mathrm{mg} / \mathrm{L}$ and an average effluent of 316 $\mathrm{mg} / \mathrm{L}$; a reduction of $39 \%$. The laboratory and the current TSS reductions from the West Virginia site were therefore similar.

TDS readings were very low, with the influent and effluent water at about 22,000 mg/L. Prior Marcellus Shale RFW tested at WVU averaged 113,000 mg/L. Looking at the water chemistry of the RFW water received at the Dytko Site may have consisted mostly of early flowback water 
(water returning back up hole in advance of gas production) and previously blended with fresh water. Comparing water quality parameters of the MTU influent and effluent to the values determined to be critical by the Industry Contact Group detailed in Table 1, both met the criteria with the exception of iron, barium and strontium.

Table 11: $\quad$ Marcellus Shale Site Water Chemistry

\begin{tabular}{|crrrr|}
\hline & $\begin{array}{r}\text { Avg Influent } \\
\mathrm{mg} / \mathrm{L}\end{array}$ & $\begin{array}{r}\text { Avg Effluent } \\
\mathrm{mg} / \mathrm{L}\end{array}$ & $\begin{array}{r}\text { Avg Change } \\
\mathrm{mg} / \mathrm{L}\end{array}$ & $\begin{array}{r}\text { Avg Change, } \\
\%\end{array}$ \\
\hline $\mathrm{Cl}$ & 15400 & 12300 & -3100 & -20 \\
\hline SO $_{4}$ & 24 & 24 & 0 & 0 \\
\hline TDS & 21300 & 22600 & 1300 & 6 \\
\hline TSS & 360 & 244 & -116 & -32 \\
\hline $\mathrm{Ba}$ & 35 & 37 & 2 & 8 \\
\hline $\mathrm{Ca}$ & 2660 & 2740 & 80 & 3 \\
\hline $\mathrm{Fe}$ & 17 & 18 & 1 & 2 \\
\hline $\mathrm{Mg}$ & 293 & 308 & 15 & 5 \\
\hline $\mathrm{K}$ & 117 & 127 & 10 & 9 \\
\hline $\mathrm{Na}$ & 5620 & 5830 & 210 & 4 \\
\hline $\mathrm{Sr}$ & 360 & 364 & 4 & 1 \\
\hline
\end{tabular}

\section{Lessons Learned}

Water collected for testing from the West Virginia site had very fine particles (less than 3 microns) and low TDS values (average of 21,300 mg/L). Marcellus Shale water samples tested at the WVU laboratory during Phase I of the project as well as additional testing conducted at the beginning of Phase II to finalize filter media selections had significantly larger particles (over 100 microns) and a much higher TDS (average of 113,000 mg/L). Although RFW treatment results met industry requirements for recycling, additional analyses of the influent and effluent water stream may have been able to clarify the initial water quality results of the raw RFW received at the Dytko Site.

\section{Project Summary}

Shale gas production depends on the creation of permeability within an otherwise nearly impermeable rock formation. Horizontal drilling and hydraulic fracturing have been applied to produce natural gas from tight shale formations previously thought to be non-obtainable. 
Hydraulic fracturing (fracking) uses large volumes of water to create numerous channels within the shale formation. Sand, pumped with the water, props open the hydraulic fractures, thus providing multiple, permeable flow paths for the natural gas. However, the withdrawal of local water resources for fracking and the returned frac water (RFW) create two significant environmental issues that must be dealt with. The search for a way to mitigate the situation and improve the overall efficiency of shale gas production suggested treatment of the RFW that would allow for the water to be recycled and reused for successive fracking operations. This would reduce the demand on local water resources and provide an economical and environmentally friendly way to manage the RFW. Project objectives were to identify the composition of RFW, define industry standards for the quality of make-up water used for fracking, and develop a technique to treat RFW for blending recycling.

Several samples of Marcellus Shale RFW were obtained and analyzed throughout the course of this project. Table 12 provides an overview of various chemical parameters acknowledging RFW is best characterized by providing a range of values for each. Differences in parameter values from sample to sample may be the result of 1) when the sample was taken during flow back, 2) the water quality characteristics of the original frac water because sources of make-up water vary, 3) chemical additives blended with the frac water since each company has their own mixture which is often proprietary, and/or 4) differences throughout the formation itself.

\section{Table 12: $\quad$ RFW Chemical Analyses}

\begin{tabular}{|c|r|r|}
\hline & Raw RFW Samples & Industry Guidelines \\
\hline TDS & $9730-188000$ & 50000 \\
\hline Hardness & $923-63400$ & 26000 \\
\hline $\mathrm{SO}_{4}$ & $\mathrm{nd}-414$ & 50 \\
\hline $\mathrm{Cl}$ & $4600-80400$ & 45000 \\
\hline $\mathrm{Na}$ & $2060-45400$ & 36000 \\
\hline $\mathrm{Ca}$ & $319-21000$ & 8000 \\
\hline $\mathrm{Mg}$ & $31-2200$ & 1200 \\
\hline $\mathrm{K}$ & $\mathrm{nd}-701$ & 1000 \\
\hline $\mathrm{Fe}$ & $6-59$ & 10 \\
\hline $\mathrm{Ba}$ & $0-1640$ & 10 \\
\hline $\mathrm{Sr}$ & $<1-3559$ & 10 \\
\hline
\end{tabular}

*Treated by FilterSure multiple module multi-media filtration system

Industry standard for acceptable RFW water quality standards continue to evolve. When contacted, the consensus from the Industry Contact Group concerning acceptable water quality for recycled RFW indicated TSS values below 20 microns along with a range of other parameters also provided in Table 12 above. Concerns with sediment accumulations in the pores and well bore were reflected by industry's TSS requirements. The other chemical 
parameters were thought to interfere with the performance of the frac water and/or potentially increase scale formation. Dissolved solids removal was important but not critical because most of the industry criteria could be achieved with blending of the treated RFW and fresh water.

Based on industry input and preliminary analyses of RFW samples, the WVU project team proceeded to determine an efficient and effective method to treat RFW for recycling purposes. Filtration was determined to be a necessary treatment step, possibly coupled with a process for removing salts. Various processes were examined such as reverse osmosis (RO), nanofiltration and electro-coagulation (EC). Upon review of costs and operational requirements of the various processes, further evaluation of EC was recommended.

Several RFW samples were obtained from various Industry Contact Group members. Samples were treated by a small-scale EC unit and a 2-gpm process demonstration unit (PDU) of the FilterSure multiple module, multi-media filtration system. Laboratory analyses showed that pretreatment of the water by EC prior to the FilterSure PDU filtration system was not required to meet the water quality criteria of industry at that time for recycling RFW. These results led to the design and construction of a mobile treatment unit (MTU) utilizing the FilterSure multiple module, muti-media technology to field test.

A fully-automated MTU was designed, constructed and delivered to a Utica Shale site in Carrollton, Ohio during September 2011. The MTU consisted of two FilterSure filtration units each capable of operating between 60 and $70 \mathrm{gpm}$. Operations at the Utica Shale site were followed by operations at a Marcellus Shale site location near Wheeling, West Virginia. Capacity of the MTU was adequate to support field operations at both sites. The mobile unit was able to keep up with on-going fracking operations and produce a quality effluent for blending with fresh water and used for subsequent fracturing operations thus reducing the overall quantity of fresh water needed for fracking operations and providing a cost-effective, environmentallysound alternative for managing RFW. Over 600,000 gallons of water were treated at the two locations with $98.6 \%$ of the water being recycled. The remaining $1.4 \%$ was used to backwash the filtration units and then disposed of properly. Suspended solids were reduced by one-third, particles as small as 0.5 microns were removed, and reduction in some divalent ion concentrations were observed during field testing. The MTU was able to handle water containing a highly-viscous oil and polymer mixture that was part of the RFW to be treated at the Utica Shale site in Ohio. Overall, the MTU proved to be highly capable of responding to "upset" conditions and treating RFW with widely variable concentrations of various chemical water quality parameters. 


$\begin{array}{ll}\text { Acronyms, } & \text { Abbreviations and Units of Measurement } \\ \text { avg } & \text { average } \\ \mathrm{Ba} & \text { Barium } \\ \text { bpd } & \text { barrels per day, barrels/day } \\ \mathrm{Ca} & \text { Calcium } \\ \mathrm{Cl} & \text { Chloride } \\ \mathrm{cndctvty} & \text { conductivity } \\ \mathrm{DOE} & \text { Department of Energy } \\ \mathrm{EC} & \text { Electro-coagulation } \\ \mathrm{ECFS} & \text { Electro-coagulation and FilterSure } \\ \mathrm{Fe} & \text { Iron } \\ \mathrm{FOA} & \text { Funding Opportunity Announcement } \\ \mathrm{gm} & \text { gram } \\ \mathrm{gpm} & \text { gallons per minute } \\ \mathrm{HMI} & \text { Human Interface Machine, Touchscreen } \\ \mathrm{K} & \text { Potassium } \\ \mathrm{KCl} & \text { Potassium Chloride } \\ \mathrm{K}_{2} \mathrm{SO} \mathrm{H}_{4} & \text { Potassium Sulfate } \\ \mathrm{kVA} & \text { kilovolt ampere } \\ \mathrm{Mg} & \text { Magnesium } \\ \mathrm{mg} / \mathrm{L} & \text { milligrams per liter } \\ \mathrm{mL} & \text { milliliters } \\ \mathrm{MTU} & \text { Mobile Treatment Unit } \\ \mathrm{Na} & \text { Sodium } \\ \mathrm{NaCl} & \text { Sodium Chloride } \\ \mathrm{NETL} & \text { National Energy Technology Laboratory } \\ \mathrm{O} \& \mathrm{G} & \text { Oil and Grease } \\ \end{array}$




\begin{tabular}{|c|c|}
\hline Pct Rtn & percent $(\%)$ return \\
\hline PDU & Process Demonstration Unit \\
\hline PSD & Particle Size Distribution \\
\hline psi & pounds per square inch \\
\hline psig & pounds per square inch gauge \\
\hline RFW & Return Frac Water \\
\hline RO & Reverse Osmosis \\
\hline $\mathrm{SO}_{4}^{-2}$ & Sulfate \\
\hline $\mathrm{Sr}$ & Strontium \\
\hline TDS & Total Dissolved Solids \\
\hline TSS & Total Suspended Solids \\
\hline WVU & West Virginia University \\
\hline w/ & with \\
\hline $\mathrm{w} / \mathrm{w}$ & wet weight \\
\hline$\mu \mathrm{M}$ & micro-meter \\
\hline$\mu \mathrm{S} / \mathrm{cm}$ & micro-siemens per centimeter \\
\hline$\mu \mathrm{S} / \mathrm{cm}^{2}$ & micro-siemens per square centimeter \\
\hline
\end{tabular}

